\title{
Greek Astronomical Tables in the Papyrus Carlsberg Collection (with associated fragments from other collections)
}

\author{
Plates XV-XX \\ Alexander Jones (New York) and Marco Perale (Oxford)
}

\begin{abstract}
The article includes A) an introduction on the Greek and Demotic astronomical papyri from the Papyrus Carlsberg Collection in Copenhagen, their provenance and relation to the Tebtunis Temple Library; B) a commented edition of five Greek astronomical tables from the Copenhagen Collection, with associated fragments from the Vitelli Institute in Florence and the Berlin Papyrussammlung.
\end{abstract}

Keywords: astronomy, almanac, template, Tebtunis

The Papyrus Carlsberg Collection has a special place in the history of modern research on ancient astronomy: the foundation of the collection, coinciding with Otto Neugebauer's sojourn in Copenhagen during the later 1930s, instigated Neugebauer's first studies of Egyptian and Greek astronomical papyri, which opened up a rich source of information about ancient astronomical and astrological theories and practices and their transmission. ${ }^{1}$ The first papyri of astral contents to receive attention were the Hieratic-Demotic P.Carlsb. 1 and the Demotic P.Carlsb. 9, representative of two categories of Egyptian-language material present in the collection: texts relating to the ancient Egyptian astronomical heritage (additionally P.Carlsb. 1a, 228, 496, 497, and 651), and calendrical and astronomical tables (additionally P.Carlsb. 31 [+ PSI inv. D 58], 32, and 638). ${ }^{2}$ The collection

\footnotetext{
* The authors wish to thank Kim Ryholt for access to and manifold assistance with the papyri in the Carlsberg Collection, and likewise to Guido Bastianini and Fabian Reiter for those respectively in the PSI collection in Florence and the Berlin Papyrus Collection. The photographs of the fragments are, respectively, courtesy of the Papyrus Carlsberg Collection, the Istituto Papirologico Vitelli, Florence, and the Ägyptisches Museum und Papyrussammlung, Staatliche Museen zu Berlin, Preußischer Kulturbesitz.

1 A. Volten, 'The Papyrus-Collection of the Egyptological Institute of Copenhagen', Archív Orientální 19, 1951, 70-74; N.M. Swerdlow, 'Otto E. Neugebauer (26 May 1899 - 19 February 1990)', Proceedings of the American Philosophical Society 137, 1993, 138-165; A. Jones, 'The Place of Astronomy in Roman Egypt', in T.D. Barnes (ed.), The Sciences in Greco-Roman Society, Edmonton, 1995 (= Apeiron 27.4, 1995), 25-51, esp. 39-41.

${ }^{2}$ H.O. Lange and O. Neugebauer, Papyrus Carlsberg No. 1, ein hieratisch-demotischer kosmologischer Text, Kongelige Danske videnskabernes selskab, Historisk-filologiske Skrifter 1.2, Copenhagen, 1940; O. Neugebauer and A. Volten, 'Untersuchungen zur antiken Astronomie IV:
} 
has also long been known to contain numerous Demotic astrological texts, though none has as yet received formal publication. ${ }^{3}$ Greek texts account for a comparatively small fraction of the collection, ${ }^{4}$ and it is only recently that several fragments of astronomical tables in Greek script have been identified. The five papyri edited below, together with P.Carlsb. 77 verso (published elsewhere by the present authors), ${ }^{5}$ appear to be the totality of the Greek astronomical tables in the inventoried part of the Papyrus Carlsberg Collection. Interestingly, no nontabular astronomical texts or astrological texts in Greek have so far come to light in the collection.

The 'Papyrus Carlsberg Collection' papyri derive from diverse Egyptian sites, but a substantial fraction of them are known to have come from clandestine excavations at Tebtunis and specifically from a Roman-period temple complex there; ${ }^{6}$ we follow recent practice in referring to these papyri as belonging to the 'Temple Library', while noting that the strict validity of this designation remains disputed. ${ }^{7}$

ein demotischer astronomischer Papyrus (Pap.Carlsberg 9)', Quellen und Studien zur Geschichte der Mathematik, Astronomie und Physik B 4, 1938, 383-406 and plate 1. (The editions in this publications have been superseded.) For a current list of published Carlsberg Papyri, with bibliography, see the website of the collection, $<>$.

3 Volten, 'Papyrus-Collection' (see note 1), 73-4; M. Chauveau, 'Un traité d'astrologie en écriture démotique', CRIPEL 14, 1992, 101-105; A. Winkler, 'On the Astrological Papyri from the Tebtunis Temple Library', in G. Widmer and D. Devauchelle (ed.), Actes du IX congrès international des études démotiques Paris 31 août- 3 septembre 2005, Cairo, 2009, 361-375. The first of several projected volumes in the series The Carlsberg Papyri devoted to astrological texts, under the general editorship of Kim Ryholt, is in preparation.

${ }^{4}$ An inventory by Marco Perale of Greek texts in published and unpublished Carlsberg papyri is in preparation.

5 PSI inv. D 92 verso + P.Carlsb. 77 verso, published in A. Jones and M. Perale, 'Dai Papiri della Società Italiana 12', Comunicazioni dell'Istituto Papirologico «G. Vitelli» 9, 2011, 40-51. For the sake of completeness, though it barely qualifies as either Greek or astronomical, we here mention P.Carlsb. 133 verso + P.Yale inv. 453, a Demotic text with a list of numbers in Greek numerals and planets in Demotic, placed after the colophon, which is unusually written in Greek;

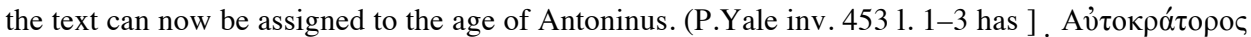

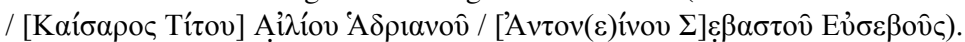

${ }^{6}$ The Carlsberg Collection originated in purchases of papyri in the 1930s, a large fraction of which derived from clandestine digging at Tebtunis. Many proved to belong to the same manuscripts as papyri recovered during the Italian excavations at Tebtunis, and in order to reunite such dispersed fragments exchanges between the two collections took place during the mid 20th century; see I. Andorlini, 'La collezione dei papiri demotici dell'Istituto Papirologico «Girolamo Vitelli» a Firenze', in F. Hoffmann and H.J. Thissen (ed.), RES SEVERA VERUM GAUDIUM Festschrift für Karl-Theodor Zauzich zum 65. Geburtstag am 8. Juni 2004, Leuven, 2004, 13-26, esp. 20.

${ }^{7}$ K. Ryholt, 'On the Content and Nature of the Tebtunis Temple Library', in S. Lippert and M. Schentuleit (ed.), Tebtynis und Soknopaiu Nesos. Leben im römerzeitlichen Fajum, Wiesbaden 2005, 141-163, esp. 143-146 (arguing for the designation as a library); T.M. Hickey, 'Tebtunis on the Arno (and Beyond). Two "Archives"', in G. Bastianini and A. Casanova (ed.), 100 anni di istituzioni fiorentine per la papirologia, Firenze, 2009, 67-81, esp. 75 (suggesting that the find may comprise several deposits). The question is complicated by the fact that different parts of the temple site were excavated over an interval of more than three decades by Grenfell and Hunt, 
With the exception of P.Carlsb. 239, all the tables published here, and indeed all the known astrological and astronomical papyri in the collection, are likely to derive from the Tebtunis temple site; and the same is probably true not only of astronomical tables found in the Italian excavations at Tebtunis, ${ }^{8}$ but also of most or all of the several astronomical and astrological papyri recovered in Grenfell and Hunt's excavations at Tebtunis in 1899/1900. ${ }^{9}$ The association of so many astral papyri, which were for the most part the resources for the practice of astrology, with a Roman period Egyptian temple complex is a circumstance of much significance for our knowledge of the social and institutional settings of Greco-Egyptian astronomy and astrology. ${ }^{10}$

Rubensohn, and Anti as well as intermittent clandestine excavators whose finds passed through dealers to several European and American collections; see C. Gallazzi, 'Fouilles anciennes et nouvelles sur le site de Tebtynis', Bulletin de l'Institut français d'archéologie orientale 89, 1989, 179-191. The relative proportions of literary, subliterary, and documentary material and of Greek and Egyptian language varied significantly from one find to another, though bits of the same papyrus roll could turn up in finds spread over several decades, as in the case of the planetary almanacs in section IV below.

8 PSI inv. D 95 recto (formerly PSI inv. provv. 75 D recto, for which see section IV below); PSI inv. D 92 verso + P.Carlsb. 77 verso, published in Jones and Perale, 'Dai Papiri' (note 5 above); probably also PSI inv. D 93 recto (ibid.).

${ }^{9}$ These include the Greek astronomical tables P.Tebt. II 274 [M.-P. ${ }^{3} 2034+2016=$ LDAB 4614: possibly from the same manuscript as P.Lund. V 35b as suggested by O. Neugebauer, 'Astronomical Papyri and Ostraca: Bibliographical Notes', Proceedings of the American Philosophical Society 106, 1962, 383-391, esp. 386 and 388]; P.Tebt. suppl. 1719 (formerly E.E.S. inv. 79/1 (1)b) [M.-P. ${ }^{3} 2033.42=$ LDAB 4386, published in A. Jones, 'Three Astronomical Tables from Tebtunis', ZPE 121, 1998, 211-218]; P.Tebt. suppl. 1721 (formerly E.E.S. inv. 79/82 (1)) [M.-P. ${ }^{3}$ 2033.4 = LDAB 4299, published in Jones, ibid.]; P.Tebt. suppl. 1720 (formerly E.E.S. inv. 79/82 (2)) $\left[\right.$ M.-P. ${ }^{3} 2033.41=$ LDAB 4387, published in Jones, ibid., see note 22 below], P.Tebt. II 449 [M.-P. ${ }^{3} 2035=$ LDAB 4615]; and the Greek astrological texts P.Tebt. II 276 [M.-P. ${ }^{3} 2051$ = LDAB 5003], P.Tebt. II 277 [M.-P. ${ }^{3} 2052$ = LDAB 5220], and P.Tebt. II 676 [M.-P. 2366 = LDAB 4616, published as GMP II 13 in I. Andorlini, ed., Greek Medical Papyri 2, 183-199]. The probability that these papyri were all found at the temple site is inferred from the so-called T-numbers inscribed on them by Grenfell and Hunt; see the discussion by R. Flemming and A.E. Hanson in Greek Medical Papyri 2, 188-189 and E.R. O'Connell, 'Recontextualizing Berkeley's Tebtunis Papyri', in J. Frösén, T. Purola, and E. Salmenkivi, eds., Proceedings of the 24th International Congress of Papyrology Helsinki, 1-7 August, 2004, Commentationes Humanarum Litterarum 122:2, Helsinki, 2007, 807-826, esp. 815-819. Four Greek tables from the 'P.Tebt. Tait' box, published in A. Jones, 'More Astronomical Tables from Tebtunis', ZPE 134, 2001, 211-220 were purchased by Grenfell and Hunt, so that their precise findspot cannot be established.

10 Jones, 'The Place of Astronomy' (note 1 above); J. Dieleman, 'Stars and the Egyptian Priesthood in the Graeco-Roman Period', in S.B. Noegel, J. Walker, and B.M. Wheeler, eds., Prayer, Magic and the Stars in the Ancient and Late Antique World, University Park (PA), 2003, 137-153. The papyrological evidence for temple-based astrological practice at Tebtunis is in many respects complementary to the evidence of the ostraca from Medinet Madi, for which see M. Ross, 'An Introduction to the Horoscopic Ostraca of Medînet Mâdi', EVO 29, 2006, 147-180, 'A Continuation of the Horoscopic Ostraca from Medînet Mâdi', EVO 30, 2007, 153-171, and 'Further Horoscopic Ostraca from Medînet Mâdi', EVO 32, 2009, 61-95. 


\section{P.Carlsb. 104, perpetual almanac for Jupiter (Plate XV)}

The papyrus, which comes from the Tebtunis 'Temple Library', comprises five noncontinguous fragments: Fr. $1(10 \times 15.5 \mathrm{~cm}) ; 2(9 \times 10.5 \mathrm{~cm}) ; 3(8 \times 15 \mathrm{~cm})$; $4(0.5 \times 4.5 \mathrm{~cm}) ; 5(6 \times 8 \mathrm{~cm})$. The table is written across the fibres, while on the recto are remains of a Demotic astrological text (as yet unpublished). ${ }^{11}$ The Greek text was in all likelihood secondarily inscribed, and probably occupied only a part of the verso since there exist many other fragments of the Demotic text having blank versos or indistinct traces in a different ink.

Fr. 1 preserves a lower margin of $6.5 \mathrm{~cm}$, and a left margin of $5.5 \mathrm{~cm}$, indicating the beginning of the table (but not necessarily the beginning of the original roll). An equivalent lower margin is in Fr. 3 (2.5 cm in Fr. 2), which may also

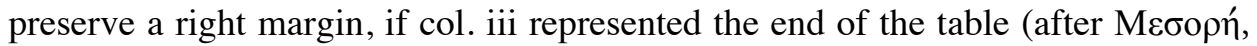
the last month in a calendar year, there are no traces of a separate column dedicated to the Epagomenae). In Fr. 1 and 3 there is $0.5 \mathrm{~cm}$ vacant of writing above the first line: it is difficult to say whether the blank space in Fr. 1 and 3 was part of the upper margin, for at the same level in Fr. 2.1 some trace of writing is visible, though this is likely to have been a general heading for the table. If the upper margin measured around $5 \mathrm{~cm}$, like the lower, the estimated roll height would have been about $20 \mathrm{~cm}$. The placement of Fr. 5, which apparently shows a succession of numbers in the twenties, but preserves both a right and a lower margin, is not clear; it may have belonged to a different table.

The table is written by two very similar, but not identical hands, which are compatible with the dating to the reign of Nero (or more broadly to the second half of the first century) that we shall argue for below from the contents of the table: for dated parallels from the reign of Nero, cf. P.Oxy. XLIX 3487 (Receipt for part-repayment of Loan, AD 65) and XLI 2971 (Contract of apprenticeship, AD 66). The first hand of our papyrus wrote the portion of text corresponding to Fr. 1 + Fr. 2 cols. i-iii., the second the one in Fr. 2 cols. iv-vi + Fr. 3-4. The part of the table represented by the right half of Fr. 2 and Fr. 3 and 4 was probably written before the left side of the table. A system of horizontal ruled lines in rather faint black ink, not reproduced in our transcriptions, marks the sequence of regnal years only in the first part of the table, i.e. Fr. $1+$ Fr. 2 cols. i-iii. Along the left part of Fr. 2 one set of these rulings was drawn rather inaccurately, so that the ruled lines cross into the letters at mid height, and a second set of rulings had to be then drawn underneath. Vertical rulings in black ink separate the columns of the left part of the table whereas no rulings are visible in the right part.

\footnotetext{
11 The text, which contains references to planets, intervals of time, and the death of an individual, appears to have no relation to the astronomical table on the other side of the papyrus beyond their common connection with the practice of astrology. We are grateful to Jacco Dieleman for providing us with a provisional description of this text. More fragments belonging to the same manuscript, but apparently not bearing the astronomical table on the verso, are in the Carlsberg Collection and that of the PSI at the Istituto Vitelli (Florence).
} 
The scribe's treatment of the names of zodiacal signs is erratic. Short names are given complete, but without consistency in the choice of case: $\Lambda \dot{\varepsilon} \omega v$ is always nominative, Kpıô genitive, and Zvy⿳⺈ dative. There are inconsistencies in the abbreviation of signs: Gemini is always $\Delta t \delta v$ except in Fr. 2 col. i $2 \Delta t \delta v \mu(\omega v)$ and Fr. 3 col. iii $3 \Delta ! \delta v \mu_{. .}$. Aquarius and Capricorn are spelled respectively Y $\delta \rho v$ and Ar $\gamma \omega$, possibly abbreviations either for the genitive ' $Y \delta \rho(o \chi o ́ o) v$ and Ai $\gamma\left(\right.$ ó$^{-}$ $\kappa \varepsilon \rho) \omega$, or for the mispelled nominative Y $\delta \rho v \chi 00 \varsigma$ and A $\gamma \omega \kappa \varepsilon \rho \omega \varsigma$. I $\chi \theta \mathrm{l}$ (Pisces) stands either for ' $I \chi \theta \dot{v}(\omega v)$ in an iotacistic spelling or ' $I \chi \theta(v \dot{\sigma})$ t. See also the paleographical notes on v $5 \mathrm{~K} \alpha \rho \kappa$ and vi $10 \Sigma \kappa о \rho \pi$ below.

\section{Transcription}

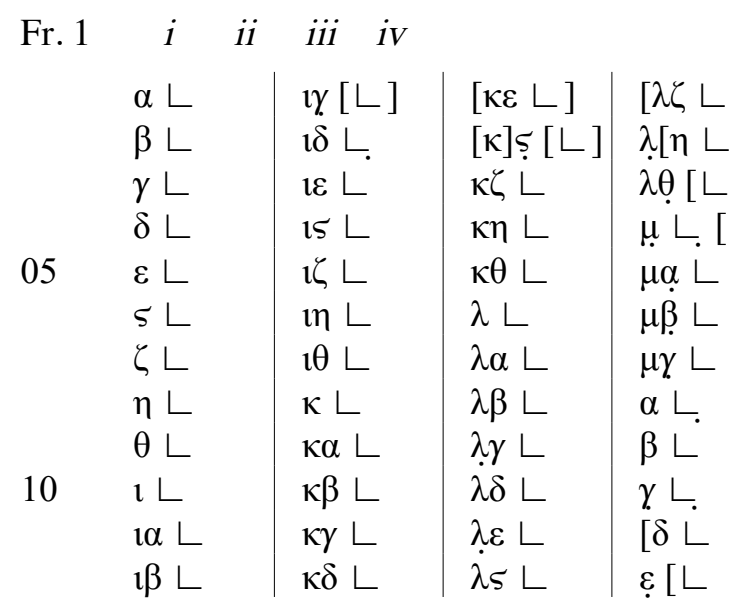

Fr. 2

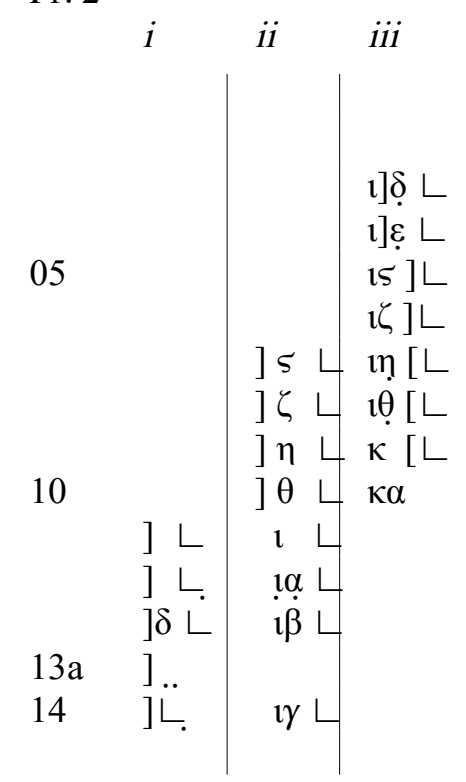

\begin{tabular}{|c|c|c|c|c|}
\hline \multirow[t]{2}{*}{ iv } & \multicolumn{3}{|c|}{ V } & $v i$ \\
\hline & & $\Theta \hat{\omega} \theta$ & & $\Phi \alpha \hat{\omega} \varphi[\mathrm{l}$ \\
\hline$\alpha\llcorner$. & & Kọpiov & & Kpiov \\
\hline$\beta\llcorner$. & & $\ddot{\Delta} \mathrm{t} \delta v$ & & $\Delta \mathrm{t} \delta \mathrm{v}$ \\
\hline$\gamma\llcorner$ & $\overline{\varphi \beta}$ & Карк & & Каркє \\
\hline$\delta\llcorner$ & & Каркє & $\bar{\eta}$ & $\Lambda \varepsilon \omega[v$ \\
\hline$\varepsilon\llcorner$ & & $\Lambda \varepsilon \omega \nu$ & & $\Lambda \varepsilon \omega \nu$ \\
\hline$\varsigma\llcorner$ & & $\Pi \alpha \rho \theta$ & & $\Pi \alpha \rho \dot{\theta}$ \\
\hline$\zeta\llcorner$ & & 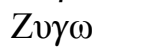 & & 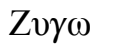 \\
\hline$\eta\llcorner$ & & $\Sigma \kappa о \rho \pi$ & & $\Sigma \kappa о \rho \pi$ \\
\hline$\theta\llcorner$ & {$[.]$.} & Tọ̆o $\beta^{\prime \prime}$ & & То $\xi_{0}$ \\
\hline ! ᄂ & & Ạı & & 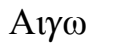 \\
\hline $1 \alpha\llcorner$ & & Y $\delta \rho v$ & & Y $\delta \rho v$ \\
\hline $1 \beta\llcorner$ & & $\mathrm{I} \chi \theta_{\mathrm{l}}$ & & $\Gamma$ \\
\hline
\end{tabular}


Col.i 13-4: after lacuna, indistinct traces at mid height ii 11: a dot (accidental?) at mid height,

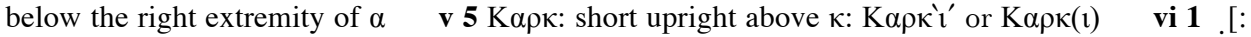
curve (?), bottom left: $\alpha, \varepsilon, \theta, o, v, \omega 4$ Before $\Delta \mathrm{t} \delta v$, a short stroke at mid height, probably accidental $10 \Sigma \kappa о \rho \pi$ : short upright above $\pi$ : $\Sigma \kappa \circ \rho \pi \iota^{\prime}$ or $\Sigma \kappa \circ \rho \pi(\mathrm{l}) \quad$ 13a: supralinear text 14. [: upper part of an upright: probably ! $[\chi \theta \mathrm{u}$

Fr. 3

\begin{tabular}{|c|c|c|c|c|}
\hline$i$ & & ii & & $\dddot{i i i}$ \\
\hline 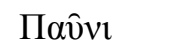 & & 'Е $\pi \varepsilon i ́ \pi$ & & 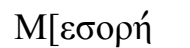 \\
\hline $\bar{\gamma} \quad \Delta \mathrm{t} \delta v^{\prime} \mu(0$ & $\omega v)$ & $\Delta \mathrm{l} \delta v$ & & $\Delta[\mathrm{l}] \delta \mathrm{v}$ \\
\hline$\Delta \mathrm{t} \delta \mathrm{v}$ & & $\Delta \mathrm{l} \delta v$ & & $\Delta \mathrm{l} \delta v \mu$ \\
\hline Каркı & & К $\alpha \rho \kappa \imath$ & & K $\alpha \rho \kappa \imath$ \\
\hline$\Lambda \varepsilon \omega v$ & & $\Lambda \varepsilon \omega v$ & & $\Lambda \varepsilon \varphi \omega \varphi$ \\
\hline$\overline{\kappa \zeta} \Pi \alpha \rho \theta \beta^{\prime \prime}$ & & $\Pi \alpha \rho \theta$ & & $\Pi \alpha \dot{\alpha} \theta \underline{\varepsilon}$ \\
\hline$\Pi \alpha \rho \theta$ & & $\Pi \alpha \rho \theta$ & $\bar{\delta}$ & $Z[v \gamma] \omega \beta^{\prime \prime}$ \\
\hline Zv $\gamma \omega$ & & Zvy. & $\bar{\alpha}$ & {$[\Sigma \kappa о \rho \pi] \mathbf{\imath} \beta^{\prime \prime}$} \\
\hline Ṭo $\xi_{0}$ & $\bar{\eta}$ & $\sum \kappa \rho \rho \pi \alpha^{\prime \prime}$ & & {$[\Sigma \kappa о \rho \pi] !$} \\
\hline $\mathrm{A}] \underline{l} \gamma \omega$ & & Ai $\gamma \omega$ & $\bar{\kappa}$. & \\
\hline Y] $\rho ̣ \rho v$ & & $\mathrm{Y} \delta \rho v$ & & \\
\hline $\mathrm{I}] \chi \theta \mathrm{r}$ & & $\mathrm{I} \chi \theta \mathrm{u}$ & & \\
\hline ] & & Kpiov & $\overline{1 \alpha}$ & \\
\hline
\end{tabular}

Col. ii $9 \sum \kappa \varrho \rho \pi$ : short upright above $\pi$, cf. Fr. 2 vi $10 \quad 12$ I $\chi \theta$ t: after the second $\mathrm{u}$ at top level, beginning of an oblique descending from left to right followed by a dot $\quad$ col. iii $10 \bar{\kappa}$. [: $\overline{\kappa \alpha}, \overline{\kappa \varepsilon}$, $\overline{\kappa \varsigma}$ or $\bar{\kappa} \hat{\theta} \quad]_{\text {... }}$ : upright, then perhaps $\alpha$ and faint remains of two uprights $1 \mathrm{~mm}$ apart

Fr. 4

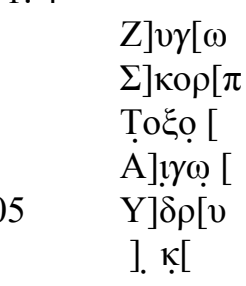

6 Possibly a numeral followed by Kฺ $\left[\rho ı v\left(\sum \kappa[0 \rho \pi\right.\right.$ would be astronomically incompatible)

Fr. 5

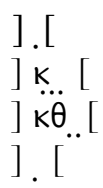




\section{Translation}

This is a schematic translation of Fr. 1-4 in their original relative placement, with restoration of the two missing regnal year columns, here designated R:i and R:ii; for justification of this organization of the fragments and the restorations see the commentary below. The successive reigns are of Augustus (1:i-iv), Tiberius (1:iv-R:ii), Gaius (R:ii), Claudius (R:ii-2:i), and Nero (2:i-iii). Nero's regnal years are extrapolated seven years beyond his historical last regnal year 14; normally these years would have been assigned to Vespasian. Column 2:iv is an index column giving cycle years. The Egyptian month names at the head of the columns of Jupiter's positions are here represented by Roman numerals. Between Fr. 2 and 3 is a gap of seven columns for the months between Phaophi (II) and Payni (X). Fr. 4 belonged to one of these columns in the lines for cycle years $7-$ 12, most likely the column to the right of 2:vi (for the month III = Hathyr), as we have placed it here. The zodiacal sign names of the papyrus are represented in the translation by the modern symbols for the signs. A numeral to the left of a zodiacal sign indicates a day number within the Egyptian month, while 1 or 2 to the right of the sign refer to the first or second stationary point.

\begin{tabular}{|c|c|c|c|c|c|c|c|c|c|c|c|c|c|c|c|}
\hline \multirow[t]{2}{*}{$1: \mathrm{i}$} & ii & iii & iv & R:i & ii & $2: \mathrm{i}$ & ii & iii & iv & $\mathrm{v}$ & vi & $4 ?$ & $3: \mathrm{i}$ & ii & iii \\
\hline & & & & & & & & & & I & II & III & $\mathrm{X}$ & XI & XII \\
\hline 1 & 13 & 25 & 37 & 6 & 18 & 4 & 2 & 14 & 1 & $r$ & $r$ & $?$ & x3 I & I I & 프 \\
\hline & 14 & 26 & 38 & 7 & 19 & 5 & 3 & 15 & 2 & II & II & $?$ & II & II & 프 \\
\hline & 15 & 27 & 39 & 8 & 20 & 6 & 4 & 16 & 3 & 12ல & ๑ & $?$ & ஒ & ช & ஒ \\
\hline & 16 & 28 & 40 & 9 & 21 & 7 & 5 & 17 & 4 & ช & $8 ภ$ & $?$ & $\delta$ & $\delta$ & $\delta$ \\
\hline & 17 & 29 & 41 & 10 & $\underline{22}$ & 8 & 6 & 18 & 5 & $\delta$ & $\delta$ & $?$ & $27 \mathrm{~m}$ & $\mathrm{P} 2 \mathrm{mp}$ & mp \\
\hline & 18 & 30 & 42 & 11 & 1 & 9 & 7 & 19 & 6 & ml & ml & $?$ & ml & ml & $4 \Omega 2$ \\
\hline 7 & 19 & 31 & $\underline{43}$ & 12 & 2 & 10 & 8 & 20 & 7 & $\Omega$ & $\Omega$ & $\Omega$ & $\Omega$ & $\Omega$ & $1 \mathrm{~m} 2$ \\
\hline 8 & 20 & 32 & 1 & 13 & 3 & 11 & 9 & 21 & 8 & $m$ & $m$ & $m$ & $\theta$ & $8 m_{1}$ & $m$ \\
\hline 9 & 21 & 33 & 2 & 14 & $\underline{4}$ & 12 & 10 & & 9 & $x x \nLeftarrow$ & $2 \theta$ & $\theta$ & rs & rs & $2 \mathrm{x} m ?$ \\
\hline 10 & 22 & 34 & 3 & 15 & 1 & 13 & 11 & & 10 & rs & rs & rs & $m$ & $m$ & $m ?$ \\
\hline 11 & 23 & 35 & 4 & 16 & 2 & $\underline{14}$ & 12 & & 11 & $m$ & $m$ & $m$ & 00 & 00 & $00 ?$ \\
\hline 12 & 24 & 36 & 5 & 17 & 3 & 1 & 13 & & 12 & 00 & $00 ?$ & $x r ?$ & $\Upsilon ?$ & $r$ & $11 \gamma$ \\
\hline
\end{tabular}

\section{Commentary}

In considering the structure and purpose of the table, it is most helpful to begin with the section comprising Fr. 2 cols. iv-vi, Fr. 3, and Fr. 4. Fr. 2 col. iv lists year numbers from 1 through 12, evidently serving as an index column. To its right are two columns of twelve rows, headed Thoth and Phaophi, the first two months of the Egyptian calendar year. The three columns of Fr. 3 are headed Payni, Epeip, and (presumably) Mesore, the last three calendar months, so we may infer that columns for the remaining seven months in order occupied the interval between Frs. 2 and 3, of which Fr. 4 is the only remnant. Obviously one is supposed to interpret the data in the first row of the table as pertaining to the twelve months of 
year 1 in sequence from left to right, and so on through the remaining eleven rows to make a sequence of data covering twelve calendar years.

Every cell of the table contains the name of a sign of the zodiac. Occasionally, this is preceded by a numeral with an overbar, and in some of these instances it is also followed by an alpha or beta and a pair of superscribed diagonal strokes. These notations call to mind a variety of astronomical table, well attested in Roman period papyri, called monthly almanacs, in which the longitudes (zodiacal locations) and phenomena of one or all of the five planets known in antiquity were recorded for a succession of calendar months and years. ${ }^{12}$ In the usual layout of a planetary almanac, the progress of time was represented only by the vertical dimension, that is, successive rows represented successive months continuing through as many years as a column of the papyrus could hold; to the right of the index column listing these months, one had either a single column containing the relevant information for a single planet, or five columns for the five planets. Alternatively, a monthly almanac could be combined with an ephemeris tabulating the daily positions of the Moon, in which case successive columns represented successive months while five rows were devoted to the five planets. In P.Carlsb. 104, both the horizontal and vertical dimensions represent time, and clearly the table can concern only a single planet. ${ }^{13}$ As in the more conventionally formatted almanacs, those cells that have merely a zodiacal sign's name represent months during which the planet remains within that sign, whereas a sign's name preceded by a numeral means either that the planet enters that sign on the day indicated by the numeral or that, while being in that sign, the planet undergoes a periodic event of its synodic cycle, such as a stationary point, that is identified by a sign or abbreviation following the sign's name. In our papyrus the only signs employed are the numeral-letters alpha and beta; these manifestly stand for the first and second stationary points.

The planet in question is easy to identify. Reading along any row from one column to the next, we see that the zodiacal sign seldom changes, implying that this is a slow planet, Jupiter or Saturn, since Mercury and Venus move on average about one sign per month while Mars averages about two signs' progress every three months. Reading down any of the preserved columns, we see that the planet's progress in one year averages about one sign, so that for example in the column for Thoth it travels through eleven signs, from Aries through Pisces, in eleven years. This must be Jupiter, which makes a complete circuit of the zodiac in about twelve years, whereas Saturn requires about thirty years for a complete circuit.

\footnotetext{
12 Jones, Astronomical Papyri from Oxyrhynchus, 2 vols. in 1, Memoirs of the American Philosophical Society 233, Philadelphia, 1999, v. 1, 44-45 and 176-177; A. Jones, 'A Classification of Astronomical Tables on Papyrus', in N.M. Swerdlow, ed., Ancient Astronomy and Celestial Divination, Cambridge (MA), 1999, 299-340, esp. 326-330.

13 The format of this almanac has a parallel in P.Tebt. suppl. 1720 (formerly E.E.S. inv. 79/82 (2)), published in Jones,'Three Astronomical Tables' (note 9 above), 214-215.
} 
Jupiter's roughly twelve year zodiacal period also offers an explanation of why the table consists of twelve rows: a table that accurately represents the motions and phenomena of Jupiter over one interval of twelve years will also represent, though with diminishing accuracy, the planet's motions and phenomena over preceding and subsequent twelve-year intervals. The left section of the table confirms that it was intended as a description of a repeating cycle. Fr. 1, cols. i-iv contain consecutive year numbers starting with 1 and continuing, twelve years to a column, until 43 in col. iv line 7, which is followed by years numbered again from 1 . (The last legible year number is 3 in col. iv line 10, though there are traces in line 12 that could have been year 5.) The number 43 has no astronomical significance relevant to Jupiter, but immediately suggests the regnal years of Augustus, so that whereas the index column Fr. 2, col. iv counted the years of an abstract repeating cycle, the columns that preceded it correlated this cycle with historic years running through several decades, apparently until the 21 st regnal year of some emperor in Fr. 2, col. iii, line 10. Extrapolating backward, we find that this emperor's first regnal year must have been inscribed in the last row of Fr. 2, col. i, and an unrecognizable trace of his name - perhaps abbreviated - is visible above the remains of the "̌́tovৎ symbol. The final regnal year of the preceding emperor, in line 13 , terminated in 4 , which limits consideration to Gaius (4 years), Claudius (14), and Nero (14). If we extrapolate from the preserved columns in Fr. 1, we can easily confirm that the 14th regnal year of Claudius falls in the eleventh row of the table, so that the regnal years in Fr. 2, cols. i-iii belong to Claudius and Nero, with Nero's years continuing beyond the actual termination of his reign (see the reconstructed sequence in the translation above).

Nero, of course, died during his fourteenth regnal year, and it is unimaginable that anyone working in the time of the Flavians would have employed an 'Era Nero' extending his regnal years beyond his death. ${ }^{14} \mathrm{We}$ can conclude that the regnal year portion of the table was composed during Nero's reign, that is, between $\mathrm{AD} 54$ and 68, since it is inconceivable that this emperor's regnal years would have been continued after his death as a continuing era.

The twelve-year cycle predicts that Jupiter will have identical longitudes on the same calendar dates at twelve-year intervals, and also that its synodic phenomena, such as stationary points, will repeat on the same dates after twelve years. In reality Jupiter's longitude increases by an average of about $5^{\circ}$ after twelve years, and the dates of the phenomena are delayed by about 8 days. Hence a table for Jupiter's motions that assumes a repeating twelve-year cycle cannot be expected to yield acceptable data by even the crudest standards known to ancient astrology for more than three or four cycles, whereas the regnal year columns of our papyrus span the better part of nine cycles. With such large shifts from one cycle to the

\footnotetext{
${ }^{14}$ Interestingly, an 'Era Titus' was used in some astronomical almanacs extending even into the reign of Hadrian (Bodl. MS Gr. Class. F 7 (P) = M.-P. ${ }^{3} 2005=$ LDAB 4505, P.Nelson = M.-P. ${ }^{3}$ $2033.5=$ LDAB 4882, P.Tebt. II 274 and P.Lund inv. 35b = M.-P. ${ }^{3} 2034+2016=$ LDAB 4614, cf. note 9 above). But there would have been no political objections to thus memorializing Titus.
} 
next, it ought to be possible to determine the range of years for which the table was originally computed by comparing its contents with Jupiter's longitudes as computed by modern astronomical theory. ${ }^{15}$ For brevity's sake, we present reconstructions according to modern theory for only the first cycle (Augustus 1-12) and the last complete cycle (Nero 2-13) in the papyrus, and we list only the zodiacal sign occupied by Jupiter at the end of those months for which a reading survives on the papyrus. Moreover we make the provisional assumption that the papyrus table operated according to the unreformed Egyptian calendar (constant years of 365 days), as was common for astronomical tables of the Roman period. Discrepancies with the papyrus's readings are indicated by bold type; a plus sign means that the sign computed by modern theory is the one that follows the sign in the papyrus in the order of increasing longitude, while a minus sign means that the recomputed sign is the one that precedes the sign in the papyrus. (Double plus means that the recomputed sign is two signs after the one in the papyrus.)

Cycle 1

\begin{tabular}{|l|l|l|l|l|l|}
\hline Year & Thoth & Phaophi & Payni & Epeiph & Mesore \\
\hline 1 & Aries & Aries & Taurus - & Taurus - & Gemini \\
\hline 2 & Gemini & Taurus - & Gemini & Gemini & Cancer + \\
\hline 3 & Cancer & Cancer & Cancer & Cancer & Cancer \\
\hline 4 & Leo + & Leo & Leo & Leo & Leo \\
\hline 5 & Leo & Virgo + & Virgo & Virgo & Virgo \\
\hline 6 & Virgo & Virgo & Virgo & Libra & Libra \\
\hline 7 & Libra & Libra & Libra & Libra & \\
\hline 8 & Scorpio & Scorpio & Sagittarius & Sagittarius + & \\
\hline 9 & Sagittarius & Sagittarius & Capricorn & Capricorn & \\
\hline 10 & Capricorn & Capricorn & Aquarius & Aquarius & \\
\hline 11 & Aquarius & Aquarius & Pisces & Pisces & \\
\hline 12 & Pisces & Pisces & & Aries & Taurus \\
\hline
\end{tabular}

\section{Cycle 8}

\begin{tabular}{|l|l|l|l|l|l|}
\hline Year & Thoth & Phaophi & Payni & Epeiph & Mesore \\
\hline 1 & Gemini ++ & Gemini ++ & Gemini & Gemini & Gemini \\
\hline 2 & Cancer + & Cancer + & Cancer + & Cancer + & Cancer + \\
\hline 3 & Leo + & Leo + & Leo + & Leo + & Leo + \\
\hline 4 & Leo + & Virgo + & Virgo + & Virgo + & Virgo + \\
\hline 5 & Virgo + & Virgo + & Virgo & Libra + & Libra + \\
\hline
\end{tabular}

15 We have added a small correction (approximately $6^{\circ}$ ) to convert modern theory tropical longitudes to the sidereal frame of reference employed in most Roman period papyri. See Jones, Astronomical Papyri from Oxyrhynchus (note 12 above), v. 1, 343 for the formula applied here, and A. Jones, 'Ancient Rejection and Adoption of Ptolemy's Frame of Reference for Longitudes', in A. Jones, ed., Ptolemy in Perspective: Use and Criticism of his Work from Antiquity to the Nineteenth Century, Archimedes 23, New York, 2010, 11-34 for discussion of the longitudinal frames of reference. 


\begin{tabular}{|l|l|l|l|l|l|}
\hline 6 & Libra + & Libra + & Libra + & Libra + & Scorpio + \\
\hline 7 & Scorpio + & Scorpio + & Sagitt +++ & Sagitt. ++ & \\
\hline 8 & Sagittarius + & Sagittarius + & Capricorn + & Capric +++ & \\
\hline 9 & Capricorn + & Capricorn + & Aquarius + & Aquarius + & \\
\hline 10 & Aquarius + & Aquarius + & Pisces + & Pisces + & \\
\hline 11 & Pisces + & Pisces + & Aries + & Aries + & \\
\hline 12 & Taurus ++ & Aries + & & Taurus + & Gemini + \\
\hline
\end{tabular}

The longitudes in the papyrus turn out to fit the first cycle very well, with discrepancies in only about $13 \%$ of the attested signs, roughly equally balanced in the two directions. This is the best fit of all the cycles; even the immediately following cycle has twice as many discrepancies, and all but one of them in the 'plus' direction. By the eighth cycle, almost all the recomputed longitudes are discrepant in the 'plus' direction.

Comparison of the dates of Jupiter's stationary points as recorded in the papyrus and as computed by modern theory seems to tell a different story: ${ }^{16}$

\begin{tabular}{|l|l|l|l|}
\hline Papyrus & Cycle 1 & $\begin{array}{l}\text { Cycle 8 (old Egyptian } \\
\text { calendar) }\end{array}$ & $\begin{array}{l}\text { Cycle 8 (reformed } \\
\text { calendar) }\end{array}$ \\
\hline 5 X 27, 2nd station & 5 VIII 25 & 5 X 17 & 5 IX 26 \\
\hline 6 XII 1, 2nd station & 6 IX 26 & 6 XI 18 & 6 X 27 \\
\hline 7 XIII 1, 2nd station & 7 X 28 & 7 XII 21 & 7 XI 30 \\
\hline 8 XI 8, 1st station & 8 VII 28 & 8 IX 24 & 8 IX 3 \\
\hline 9 I [day lost], 2nd station & 8 XI 30 & 9 I 20 & 8 XIII 4 \\
\hline 9 XII 24?, 1st station & 9 IX 4 & 9 XI 1 & 9 X 9 \\
\hline
\end{tabular}

In the first cycle, the actual stationary points were two months or more in advance of the dates in the papyrus. Agreement progressively improves in subsequent cycles, until by cycle 8 the second stationary points are in reasonably good agreement if one assumes the unreformed calendar (cycle 9 would be still closer). The first stationary points exhibit significantly larger discrepancies, which could be supposed to reflect a systematic error of a month in the ancient computation of these dates. The recorded dates of the stationary points would have to be supposed to come from a source different from that of the longitudes, since in year 6 the second stationary point, which ought to be a date of minimum longitude, is said to occur in Libra following two months when the planet is stated to be in Virgo, while in year 8 the first station, ostensibly a date of maximum longitude, is said to occur in Scorpio following a month when the planet is stated to be in Sagittarius. Yet the stationary points were clearly not added to the table after the rest had been written, since the zodiacal sign names are slightly indented following the day numbers ascribed to the stations.

\footnotetext{
16 The recomputed dates for cycle 1 are given only according to the unreformed calendar, since the divergence between the unreformed and reformed calendars was no more than one day during the years in question.
} 
An alternative explanation of the apparent displacement of the stationary points is that the indications alpha and beta in the papyrus table are not meant to identify the dates with which they are associated as the actual stations but the dates following the stations when the planet crosses a boundary between zodiacal signs; thus alpha marks the return of Jupiter in its retrograde motion into a sign that it had previously exited, and beta marks the reentry into the following sign. This interpretation is consistent with all the preserved instances of these marks, and we consider it to be more probable than the hypothesis of a fusion of sources of widely disparate date, although we do not know of any other astronomical table in which the annotations alpha and beta are used in this way.

\section{P.Carlsb. 141, template for Venus (Plate XVI)}

One fragment measuring $2.5 \times 12 \mathrm{~cm}$ preserves remains of an astronomical table written across the fibres; there are traces of Greek on the recto. The vertical and (fainter) horizontal rulings are in black ink. The hand bears a general resemblance to that of P.Carlsb. 104 Fr. $1+2$ cols. i-iii, and can be assigned to the first century. The papyrus is most likely to come from Tebtunis.

\begin{tabular}{|c|c|c|c|c|c|}
\hline \multicolumn{3}{|c|}{ Transcription } & \multicolumn{3}{|c|}{ Translation } \\
\hline & $i$ & ii & & $i$ & ii \\
\hline & ] & $\zeta[$ & & ] & 7[ \\
\hline & ] & $\eta[$ & & ] & 8[ \\
\hline & ] & $\mathrm{t}[$ & & ] & 10[ \\
\hline & ] & $! \alpha[$ & & ] & 11[ \\
\hline \multirow[t]{5}{*}{05} & 1] & $1 \beta[$ & 05 & 10] & 12[ \\
\hline & ] & $\vartheta \gamma[$ & & ] & 13 [ \\
\hline & ] & $1 \varepsilon[$ & & ] & 15[ \\
\hline & ] & .5[ & & ] & 16[ \\
\hline & ] & $! \zeta[$ & & ] & 17 [ \\
\hline \multirow[t]{5}{*}{10} & 1] $\varepsilon$ & in [ & 10 & $1] 5$ & 18[ \\
\hline & ] & $\kappa[$ & & ] & 20[ \\
\hline & ] & $\kappa \alpha .[$ & & ] & 21[ \\
\hline & ] & $\kappa \beta[$ & & ] & 22[ \\
\hline & ] & $\kappa[\gamma$ & & ] & $2[3$ \\
\hline \multirow[t]{2}{*}{15} & ] & $\kappa[\varepsilon$ & 15 & ] 20 & $2[5$ \\
\hline & ] & & & ] & $2[6$ \\
\hline
\end{tabular}




\begin{tabular}{l|ll|l}
\hline$]$ & $\kappa[\zeta$ & ] & $2[7$ \\
\hline$]$ & {[} & ] & {[} \\
\hline$]$ & {[} & ] & {[}
\end{tabular}

The fragment preserves parts of just two columns of a table. Col. i appears to be an index column tabulated only at intervals of five lines. The presence of such a column marks this small but interesting fragment as part of a template, a standardized representation of the progress of a heavenly body in longitude relative to an epoch position that the table's user would have read off a separate epoch table. ${ }^{17}$ The numbers in col. ii increase by steps of one or two; it may be presumed that these are degrees of progress from an epoch position, and that at least one further column is lost to the right, containing minutes and possibly further fractional places. A constant daily progress of $1^{\circ} 15^{\prime}$ starting with $1^{\circ} 15^{\prime}$ on day 1 would result in a series of values exactly matching the fragment's readings:

\begin{tabular}{|c|c|c|}
\hline & 1 & 15 \\
\hline & 2 & 30 \\
\hline & 3 & 45 \\
\hline & 5 & 0 \\
\hline 5 & 6 & 15 \\
\hline & 7 & 30 \\
\hline & 8 & 45 \\
\hline & 10 & 0 \\
\hline & 11 & 15 \\
\hline 10 & 12 & 30 \\
\hline & 13 & 45 \\
\hline & 15 & 0 \\
\hline & 16 & 15 \\
\hline & 17 & 30 \\
\hline 15 & 18 & 45 \\
\hline & 20 & 0 \\
\hline & 21 & 15 \\
\hline & 22 & 30 \\
\hline & 23 & 45 \\
\hline 20 & 25 & 0 \\
\hline & 26 & 15 \\
\hline & 27 & 30 \\
\hline & 28 & 45 \\
\hline & 30 & 0 \\
\hline
\end{tabular}

17 Jones, Astronomical Papyri from Oxyrhynchus (note 12 above), v. 1, 115-118; Jones, 'A Classification' (note 12 above), 311-314. 
A longitudinal motion of $1^{\circ} 15^{\prime}$ per day is possible only for Mercury and Venus, and only Venus can keep close to this velocity for twenty days, during the interval of its synodic cycle before and after its superior conjunction. In P.Oxy. astron. 4135, a detailed description of an idealized synodic cycle of Venus' motion, a velocity of precisely $1^{\circ} 15^{\prime}$ is prescribed for the 60 days of fastest motion around superior conjunction. The present template - the first to come to light pertaining to Venus - may have taken its starting point either from the planet's last morning visibility preceding superior conjunction or from the conjunction itself.

\section{P.Carlsb. 239, table of lunar mean longitudes (Plate XVI)}

The papyrus consists of one fragment, measuring $11.5 \times 14 \mathrm{~cm}$. The Greek writing runs across the fibres with no tabular ruling; on the recto there are three columns of a Demotic account. An upper margin of $2 \mathrm{~cm}$ is preserved. The text consists of three visible columns of writing: of the first, which will not be displayed here, only few illegible traces at 11. 11-12 are visible; the second (= col. i) is complete in the first 7 lines; only scanty remains of the beginning of the third (= col. ii), where the surface is badly damaged, are preserved.

The fragment is written in an informal, upright, semicursive script, bearing a general resemblance with the writing of other astronomical tables paleographically assigned to the second century, such as P.Tebt. II 274 and TCD Pap. inv. F 7.18 There are also close similarities with the hand of O.Heid. 190 (formerly published as O.Heid. 101) = Seider, Paläographie I 30, dated AD 114.

The provenance of the fragment is unknown, but the Demotic hand on the verso is clearly recognizable in other accounts from Soknopaiu Nesos.

\section{Transcription}

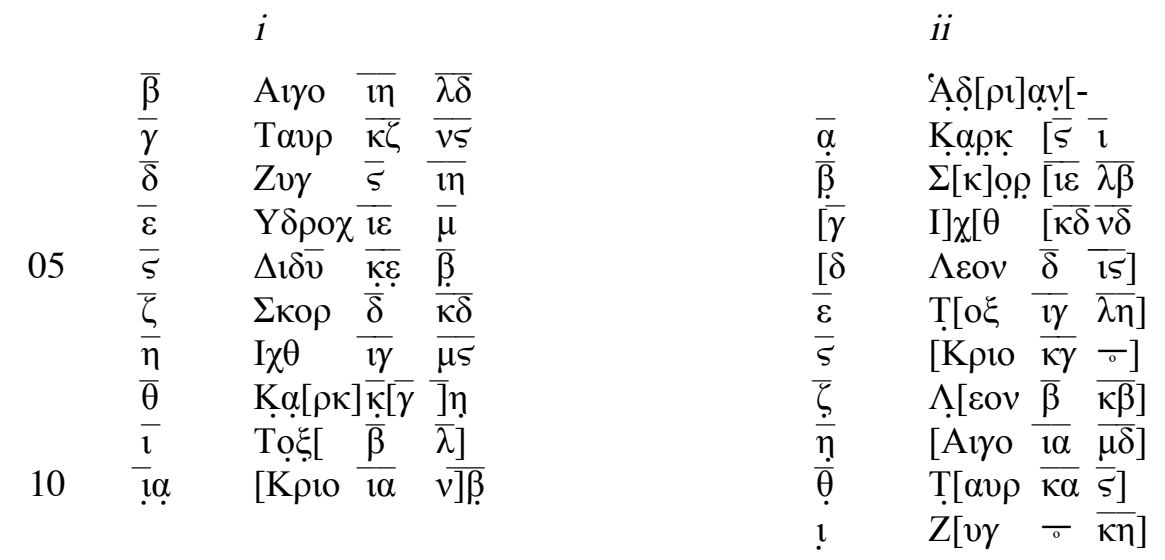

18 Photographs are available on the APIS website (berkeley.apis.297), and in ZPE 48, 1982, Tafel VI. 
Translation

\begin{tabular}{|c|c|c|c|c|c|c|}
\hline & \multicolumn{3}{|c|}{$i$} & \multicolumn{3}{|c|}{ ii } \\
\hline & 2 & Capricorn & $18^{\circ} 34^{\prime}$ & & Hadrian & \\
\hline & 3 & Taurus & $27^{\circ} 56^{\prime}$ & 1 & Cancer & $6^{\circ} \quad 10$ \\
\hline & 4 & Libra & $6^{\circ} 18^{\prime}$ & 2 & Scorpio & $15^{\circ} 32$ \\
\hline & 5 & Aquarius & $15^{\circ} 40^{\prime}$ & 3 & Pisces & $24^{\circ} 54$ \\
\hline 05 & 6 & Gemini & $25^{\circ} \quad 2^{\prime}$ & 4 & Leo & $4^{\circ} 16$ \\
\hline & 7 & Scorpio & $4^{\circ} 24^{\prime}$ & 5 & Sagittarius & $13^{\circ} 38$ \\
\hline & 8 & Pisces & $13^{\circ} 46^{\prime}$ & 6 & Aries & $23^{\circ} 0$ \\
\hline & 9 & Cancer & $23^{\circ} \quad 8^{\prime}$ & 7 & Leo & $2^{\circ} 22$ \\
\hline & 10 & Sagittarius & $2^{\circ} 30^{\prime}$ & 8 & Capricorn & $11^{\circ} 44$ \\
\hline 10 & 11 & Aries & $11^{\circ} 52^{\prime}$ & 9 & Taurus & $\begin{array}{rr}21^{\circ} & 6 \\
0^{\circ} & \end{array}$ \\
\hline
\end{tabular}

The table lists the Moon's mean longitude on the same day, probably Thoth 1, of successive Egyptian years, each year being constituted by 365 days according to the unreformed (pre-Augustan) calendar that persisted in use in astronomical contexts. The line-to-line increase in longitude is four zodiacal signs plus $9^{\circ} 22^{\prime}$, i.e. $129^{\circ} 22^{\prime}$, except in col. i $2-3$, where the increase is $128^{\circ} 22^{\prime}$, probably to be understood as an arithmetical error of the scribe.

A similar table describing the lunar mean motions during the years is transmitted by P.Oxy. astron. 4174 (I-III century), which, however, presents a different line-to-line increase $\left(142^{\circ}-129^{\circ}-129^{\circ}-129^{\circ}\right.$ in sequence), due to the reformed calendar. In 4174 another table on the back of the papyrus codex shows the moon's mean longitudinal progress through the days of a calendar year. A joint use with another table listing the number of degrees that the Moon progresses in one up to 365 days (possibly in multiples of 30 days up to 360 and in single days up to 29) would not be surprising here: adding the appropriate numbers from the different tables would give the mean Moon's position on any given day. To obtain the Moon's true position, a further addition or subtraction of a few degrees to account for the Moon's anomaly was probably expected, but it is not clear how this correction would have been calculated.

On the left side, before the name of the zodiacal signs, each column presents a succession of regnal years. Using the tables of Ptolemy's Almagest, it has been possible to determine that the regnal years are of Trajan and Hadrian, and to reconstruct all the missing/lacunose entries in both columns. ${ }^{19}$ The following recalculation of the table is based on a line-to-line difference of exactly $129^{\circ} 22^{\prime}$, except for the (presumed) mistake in col. i 2-3:

19 For this purpose we have used R. van Gent's 'Almagest Ephemeris Calculator' at http://www.staff.science.uu.nl/ gent0113/astro/almagestephemeris.htm. Recomputation by modern theory would yield identical results, since we are not looking for more precise agreement than to within a few degrees. 


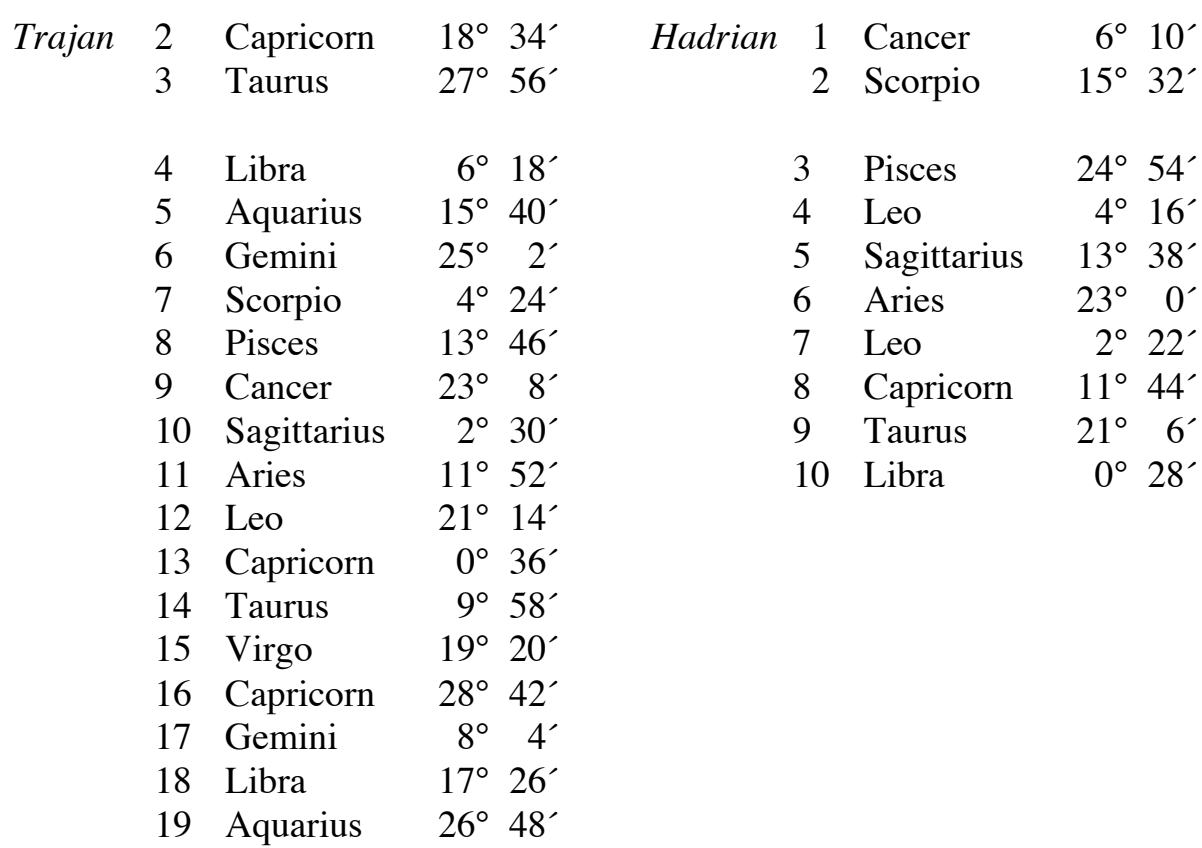

Col. i $1 \bar{\beta}$ refers to the second year of Trajan's reign, for on Thoth 1 at noon, the mean longitude of the Moon according to Ptolemy is approximately Capricorn $17^{\circ} 3^{\prime}$, which is close to col. i 2 Capricorn $18^{\circ} 34^{\prime}$. Analogously, using increments of $129^{\circ} 22^{\prime}$, the entry for line 10 (year 11) ought to be Aries $14^{\circ} 52^{\prime}$, which seems to be confirmed by the remains of a beta at the end of the column.

The ascription of the years in col. i to Trajan's times reconciles with the indication given by the scanty traces in col. ii 1 , where A $A[\rho \rho] \alpha v[-$ can be read. This means that Trajan's name appeared at the end of the preceding column, before the indication of his first regnal year. Therefore, the papyrus could possibly have contained the list of the Moon's mean motions during the reigns of Nerva, Domitian and, perhaps, Titus. The scanty traces in the (almost totally lost) preceding column, still visible in the lower extremity, are not incompatible with numerals.

Consequently, while we cannot be absolutely certain of the presence of the regnal years preceding Trajan 1, the last preserved regnal year in col. ii 11, Hadrian 10, provide a firm terminus ante quem for the writing of the table. 


\section{IV. (i) P.Carlsb. 673 + P.Berl. 14401 + PSI inv. D 94 + PSI inv. D 19/5, monthly almanac (Plates XVII-XIX)}

\section{General introduction}

The fragments edited here derive from one of a pair of rolls from the Tebtunis 'Temple Library' that bore extensive monthly almanacs ${ }^{20}$ in Greek on their rectos and Demotic literary texts on their versos. The two almanacs have enough points of similarity to make it often difficult to tell which roll a particular fragment belongs to: the tabular layout and roll height are very similar, there is an overlap in the range of dates covered, and the same hand appears in both. Fortunately the Demotic texts are different and usually identifiable, providing a criterion for distinguishing the rolls when the rectos fail to do so.

One of the rolls is represented by PSI inv. D 95 (17 fragments, formerly inventoried as PSI inv. provv. 75 D), P.Tebt. suppl. 1721 (2 fragments, formerly E.E.S. inv. 79/82(1)), and P.Yale 3609. The almanac on this roll, apparently written entirely by one hand, covered a range of years including Claudius 9 (AD 48/49) through Nero 7 (AD 60/61). The Demotic text on the verso is now identified as a composition known as the 'Song of Horus of the Vineyard'. ${ }^{21}$ The ten most substantial fragments of PSI inv. D 95 were published in 1973, and P.Tebt. suppl. 1721 in 1998; a new edition comprising all the known fragments is in preparation by the present authors. ${ }^{22}$

The other roll, edited here, is represented by 17 fragments in P.Carlsb. 673, the single large fragment P.Berl. 14401,23 and 15 fragments in PSI inv. D 94. ${ }^{24}$ Three hands (to be discussed in more detail below) can be distinguished in the almanac. We believe that one of these hands ('Hand 1') is the same as the hand that wrote PSI inv. D 95. The fragments with Hands 2 and 3, when well enough preserved to

20 See above, note 12 .

21 J.F. Quack, Einführung in die altägyptische Literaturgeschichte: die demotische und gräkoägyptische Literatur, Münster, 2005, 90.

22 M. Manfredi and O. Neugebauer, 'Greek Planetary Tables from the Time of Claudius', ZPE 11, 1973, 101-114; Jones, 'Three Astronomical Tables' (note 9 above), 211-213. At the time when the latter article was published the papyri in it were with the Egypt Exploration Society collection in Oxford; they were reunited with the main body of the papyri from Grenfell and Hunt's 1899-1900 Tebtunis season in Berkeley in 2005.

23 Acquired in unknown circumstances but likely purchased by the German papyrus cartel before 1914. Fabian Reiter informs us that there is no acquisition record for this fragment in the manuscript inventory of the Berlin Papyrus Collection. However, for several Tebtunis papyri with nearby inventory numbers in the Berlin collection, acquired through the cartel, see Gallazzi, 'Fouilles anciennes' (note 7 above), 180 note 5.

24 Excavated as part of the 'Temple Library' find in March, 1931. Six of the fragments in PSI inv. 94 were formerly in PSI inv. provv. 75 D, together with the fragments of the 'Song of Horus' roll. Manfredi (Manfredi and Neugebauer, 'Greek Planetary Tables' [note 22 above], 101 with note 2) correctly conjectured that there was a second roll, though one of his reasons has turned out to be invalid: the regnal year 10 in PSI inv. D 94 Fr. 6-7 belongs to Nero, while that in PSI inv. 95 Fr. 2 belongs to Claudius, so there is no chronological overlap involving these particular fragments. 
tell, are unfinished: the table headings (written in Hand 1) and month names (in Hand 2 or 3 ) are present, but the sections of the tables where the astronomical data should appear are entirely blank. Fragments written entirely in Hand 1 have the expected astronomical data. The Demotic text on the verso is the Book of Thoth. ${ }^{25}$ The text of this composition has to a great extent been reconstructed, enabling placement of many of the fragments bearing it within the original roll despite the almost complete absence of astronomical data on these fragments. ${ }^{26}$ Combining information derived from the rectos and the versos, we can deduce that the almanac extended certainly from Nero 3 (and very probably from Nero 1, AD 54/55) through at least Nero $12(65 / 66)$. The almanac was apparently begun by one person, who wrote the table headings (regnal years and planet names) for the full extent of the almanac, and the astronomical data for the first few years; then the task of writing the remaining columns of month names was passed on two other people, but the project was then abandoned. We offer an edition of all currently known fragments that preserve text on the recto, together with a diagram indicating the known approximate placements of fragments - including some that preserve no text.

\section{The tabular layout of the almanac}

The almanac is divided into rectangular 'almanac blocks', meant to contain all the astronomical positions and events pertaining to a single planet in a single year. The dimensions of a single block, delimited by horizontal and vertical rulings, are approximately $14 \mathrm{~cm}$ width by $9 \mathrm{~cm}$ height, sufficient to accommodate twelve text lines for the twelve months of the Egyptian year. ${ }^{27}$ These lines, which in some parts of the almanacs were separated by faint horizontal rulings, always began with the month name, immediate to the right of the left boundary of the block. (No thirteenth line for the Epagomenae was provided, so any information pertaining to them would have had to be incorporated in the line for Mesore.) A header line giving the number of the regnal year (followed by the L-shaped हैं and the name of the planet was written above the upper horizontal ruling.

Since the height of the papyrus roll was about $26 \mathrm{~cm}$, the blocks come in pairs, one directly above the other, with top and bottom margins of about $3 \mathrm{~cm}$ and a space of about $2 \mathrm{~cm}$ between the blocks. The header lines of the upper blocks

25 R. Jasnow and K.-Th. Zauzich, The Ancient Egyptian Book of Thoth, 2 vols., Wiesbaden, 2005 , v. 1,80 .

${ }^{26}$ Progress has been made in the reconstruction of the Book of Thoth since the editio princeps; see in particular J.F. Quack, 'Die Initiation zum Schreiberberuf im alten Ägypten', Studien zur Altägyptischen Kultur 36, 2007, 249-295. We are deeply indebted to Professors Jasnow, Zauzich, and Quack for identifications of the Book of Thoth and 'Song of Horus' texts on the versos of our almanac fragments. Richard Jasnow in particular has tirelessly assisted us by identifying new parallels between our fragments and other Book of Thoth manuscripts, and informing us about the work's structure and manuscript tradition.

27 The measurements associated with the layout of the almanac blocks can be directly measured on P.Berl. 14401. They are the same as those of the 'Song of Horus' roll. 
were written in the upper margin, and those of the lower blocks in the space between the upper and lower blocks. A vertical ruling about $2 \mathrm{~cm}$ to the left of the right boundary of the blocks marked off a narrow column, always left vacant, separating the blocks from their neighbors to the right. Five such pairs of blocks, running from left to right along the roll, constituted the almanac for two consecutive Egyptian years, with the planets always following the order Saturn, Jupiter, Mars, Venus, Mercury. It happens that the almanacs for the odd-numbered regnal years of both Claudius and Nero always started with the upper block of a pair, and those for the even-numbered years with a lower block, as in the schematic diagram Fig. 1.

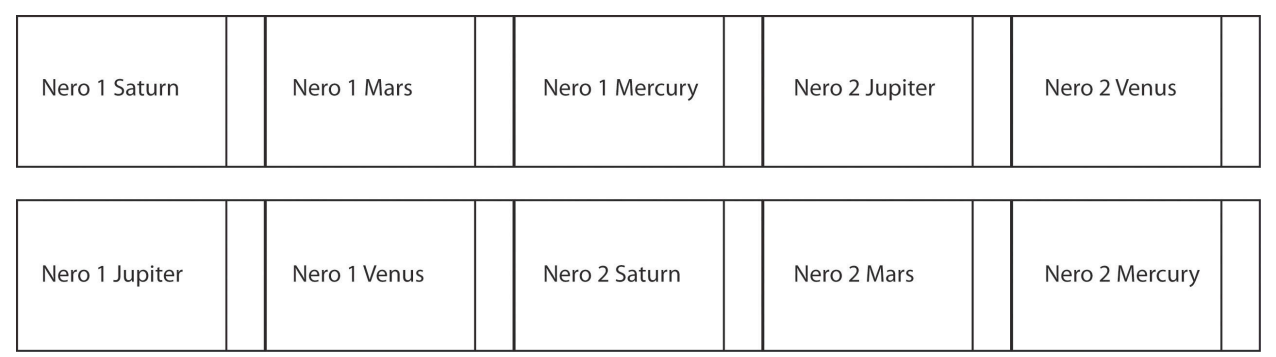

Fig. 1. Arrangement of almanac blocks for two consecutive Egyptian years

In our discussion of individual fragments, we designate the rulings as follows (Fig. 2). The four horizontal rulings from top to bottom are referred to as h1 (upper ruling of upper blocks), h2 (lower ruling of upper blocks), h3 (upper ruling of lower blocks), and h4 (lower ruling of upper blocks). The faint rulings marking off individual tabular lines when present, are designated $h^{*}$. The vertical rulings marking the boundaries between blocks are designated $\mathrm{v} 1$, and the secondary rulings about $12 \mathrm{~cm}$ to the right of the $\mathrm{v} 1$ rulings are designated $\mathrm{v} 2$. The notation $\mathrm{v}^{*}$ designates an additional vertical ruling between $\mathrm{v} 1$ and $\mathrm{v} 2$.

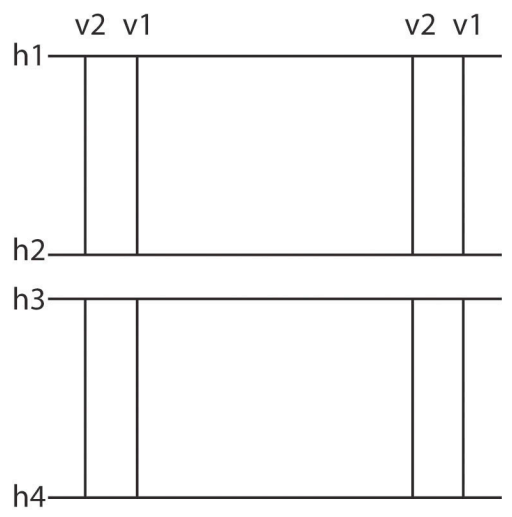

Fig. 2. Notations for the almanac rulings 
We number the vertical pairs of blocks serially from left to right, such that the first pair for the year Claudius 9 (Saturn and Jupiter) is 1. This serial number is preceded by a capital letter $\mathrm{T}$ indicating that we are dealing with the roll having the Book of Thoth on the verso. (We adopted these conventions so that a similar notation could be applied to the 'Song of Horus' roll, whose almanac contains years from Claudius 9 on.) Thus T16 is the pair of blocks for Nero 1, Saturn and Jupiter. The reference numbers are intended to serve to locate fragments in relation to a notional almanac that could be extended indefinitely in either temporal direction, not to the beginnings of the actual rolls. Imagining the papyrus as transparent so the ruling is visible on the verso, we may use the reference numbers also as a uniform scale for specifying the locations of features of the verso text; thus we may say that the right margin of a particular column of the verso text is about $9 \mathrm{~cm}$ left (verso view) of the beginning of T44.

\section{Reconstruction and description of the almanac}

The editors of the Book of Thoth have assigned to each of the many known manuscripts a name consisting of the initial letter of the present location of the principal fragment or fragments followed by a two-digit numeral; the roll we are dealing with is their B03, so named because the largest single fragment is P.Berl. 14401. Individual fragments receive numbers B03.1 etc. ${ }^{28}$ The Demotic text on the verso was written (right to left) starting at the same end of the roll as the beginning of the almanac on the recto (which of course ran from left to right), so that to switch from viewing the almanac to viewing the Book of Thoth in their correct orientations, one would have to turn the roll over from end to end, not by a vertical flip. B03 is 'stichic', that is, each verse of the Book of Thoth has a separate line; the right margin of the text columns is straight but the left margin ragged. The column width is thus variable, depending on the longest verse in each column; a typical text column seems to have been around $20 \mathrm{~cm}$ wide, while the exceptionally broad column, about $27 \mathrm{~cm}$ wide, straddling T42-T44 represents, so far as we know, the extreme. The number of lines in a text column was also variable, ranging from as few as 19 to the mid 20s. A complete, gapless text of the Book of Thoth cannot be reconstructed from the available copies, and the locations of passages preserved in fragments of B03 are therefore expressed in terms of exact or approximate parallels in other manuscripts, for example the much better preserved B02 which has a large overlap with the extant portions of B03. To show how our placements of fragments relate to (and in some cases are based on) their verso texts, we will indicate these parallels, but the reader must consult the edition of Jasnow and Zauzich for details of the texts and identifications of the individual papyri constituting the other Book of Thoth manuscripts.

\footnotetext{
${ }^{28}$ In the edition of the Book of Thoth 'B03' refers both to the entire original roll and to P.Berl. 14401; to avoid ambiguity we will use B03.0 to mean the Berlin fragment when employing these notations. Numbers beyond B03.15 have been assigned since 2005 .
} 
P.Berl. 14401, the largest single fragment from the roll, preserves the complete height, approximately $26 \mathrm{~cm}$. The almanac almost certainly began with T16 (i.e. Nero 1), since this is approximately where the beginning of the Book of Thoth text on the verso was, and the latest surviving fragments belong to T45 (Nero 12), an interval that would have consumed about $4.2 \mathrm{~m}$ of papyrus. Presuming that the copy of the Book of Thoth was complete, it would have filled about $5.5 \mathrm{~m}$, corresponding to an almanac on the recto covering at least 16 years, i.e. Nero 1 through at least Vespasian 2.

Three hands are present in the almanac. Hand 1 is almost certainly the same Greek astronomical hand from the 'Song of Horus' roll (see ZPE 11, 1973, Tafel III). It also bears a general resemblance to a literary papyrus found in the same lot by Anti, PSI X 1180, recently redated by I. Andorlini to the last quarter of the first/beginning of the second century. ${ }^{29}$ For Hand $2 \mathrm{cf}$. for instance, P.Flor. I 55 (Notification to the Strategos, 88-96). For Hand 3, cf. the principal hand in PSI X 1131 (= rr. 1-29) (Loan, AD 41), a document originating from Ptolemais Euergetis but discovered in a cellar of the Soknebtunis temple in the winter of 1931. The tabular framework of the almanac is in black ink.

As noted above, the five blocks of the almanac covering odd-numbered regnal years of Nero always began with an upper block, so that in such years the data for Saturn, Mars, and Mercury occupied upper blocks and Jupiter and Venus occupied lower blocks. The arrangement was reversed for even-numbered regnal years. Hand 1 appears to have begun the almanac, starting with Nero 1 and recording all the requisite information including header lines, month names, and astronomical data, continuing in this way at least as far as Nero 4. By Nero 8, Hand 1 has ceased to write anything except the header lines. The columns of month names from this point on are in Hand 2, or in one place (the lower block of T34) Hand 3, and the spaces reserved for the astronomical data are left blank. It is not clear why the almanac was abandoned in this incomplete state.

In a completed part of the almanac, each of the month names written next to the left boundaries of the blocks would have been followed by one or more indications of a planetary position or phenomenon occurring within that month. Only three fragments preserve such material, namely P.Carlsb. 673 Fr. 2, P.Carlsb. 673 Fr. 6, and PSI inv. D 94 Fr. 12. Of these, the latter two have only a few legible letters and are at present unplaced. The astronomical statements in P.Carlsb. 673 Fr. 2 use the following formats (where $\mathrm{d}$ is a numeral for the day number with the month, $\mathrm{s}$ is an abbreviated name of a zodiacal sign, and 1 is a numeral for the number of degrees within the zodiacal sign):

\footnotetext{
${ }^{29}$ I. Andorlini, 'Un ricettario da Tebtynis: parti inedite di PSI 1180', in I. Andorlini, ed., Testi medici su papiro. Atti dell'incontro di studio (Firenze, 3-4 giugno 2002), Firenze, 2004, 81-118, esp. $81 \mathrm{n} .2$ and plates III-IV. Other paleographical parallels for this hand are provided by Manfredi, in Manfredi and Neugebauer, 'Greek Planetary Tables' (note 22 above), 102.
} 
d s 1 (to record a planet's longitude on day d)

d s ouv (to record the entry of a planet into a zodiacal sign) ${ }^{30}$

In this fragment, the wide column has been subdivided by at least two further vertical rulings, the first presumably immediately to the right of the (lost) day numbers following the month names, and the second about $2.5 \mathrm{~cm}$ still further to the right, separating the longitude or statement of sign-entry from the day number of the next event (if any) occurring during the month. Such subdividing rulings are also found in the 'Song of Horus' almanac.

\section{Concordance of Book of Thoth roll fragments}

\begin{tabular}{|l|l|l|l|l|l|}
\hline Collection & $\begin{array}{l}\text { Publication } \\
\text { Number }\end{array}$ & $\begin{array}{l}\text { Previous Inventory } \\
\text { Number }\end{array}$ & $\begin{array}{l}\text { Jasnow/ } \\
\text { Zauzich, } \\
\text { Book of } \\
\text { Thoth }\end{array}$ & $\begin{array}{l}\text { Our } \\
\text { edition }\end{array}$ & Placement \\
\hline P.Berlin & 14401 & & B03.0 & 16 & T43-45 \\
\hline P.Carlsb. & 673.1 & & B03.10 & 7 & T33-34 \\
\hline P.Carlsb. & 673.2 & & B03.11 & 3 & T25 \\
\hline P.Carlsb. & 673.3 & & B03.5 & 8 & T33-34 \\
\hline P.Carlsb. & 673.4 & & B03.13 & 22 & \\
\hline P.Carlsb. & 673.5 & & B03.3 & 19 & T45 \\
\hline P.Carlsb. & 673.6 & & B03.15 & 23 & \\
\hline P.Carlsb. & 673.7 & & B03.2 & 20 & T45 \\
\hline P.Carlsb. & 673.8 & & B03.4 & 2 & T23 \\
\hline P.Carlsb. & 673.9 & & B03.1 & 21 & T45 \\
\hline P.Carlsb. & 673.10 & & B03.6 & 24 & \\
\hline P.Carlsb. & $673.11+12$ & & B03.7+8 & 25 & \\
\hline P.Carlsb. & 673.13 & & B03.12 & 4 & T27 \\
\hline P.Carlsb. & 673.14 & & B03.14 & 17 & T45 \\
\hline P.Carlsb. & 673.15 & & B03.24 & 26 & \\
\hline P.Carlsb. & 673.16 & & B03.23 & 9 & T35 \\
\hline P.Carlsb. & 673.17 & & B03.25 & 27 & \\
\hline PSI inv. D & $19 / 5$ & & B03.9 & 15 & T42-43 \\
\hline PSI inv. D & 94.1 & B03.16 & 1 & T18-19 \\
\hline PSI inv. D & 94.2 & B03.17 & 5 & T28 \\
\hline
\end{tabular}

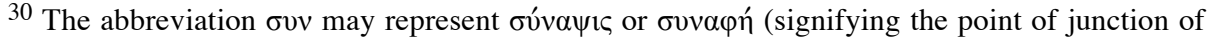
two adjacent signs or perhaps the planet's 'conjunction' with this point, a usage unrelated to the astrological concept of $\sigma v v \alpha \varphi \eta ́)$. Cf. $\sigma u ́ v \alpha \psi(\imath \varsigma$ ?) in P.Oxy. astron. 4175 for this kind of planetary event, and the discussion in Jones, 'Three Astronomical Tables' (note 9 above), 213, note to line 5.
} 


\begin{tabular}{|l|l|l|l|l|l|}
\hline PSI inv. D & 94.3 & inv.provv. 75.16 D & B03.22 & 6 & T30 \\
\hline PSI inv. D & 94.4 & inv. s.n. (a) D & B03.26 & 10 & T35 \\
\hline PSI inv. D & 94.5 & inv.provv. 336.1 D & B03.18 & 11 & T37 \\
\hline PSI inv. D & 94.6 & inv.provv. 75.10 D & B03.19 & 12 & T38 \\
\hline PSI inv. D & 94.7 & inv.provv. 75.11 D & B03.20 & 13 & T38-39 \\
\hline PSI inv. D & 94.8 & inv.provv. 184.1 D & B03.27 & 14 & T40 \\
\hline PSI inv. D & 94.9 & inv.provv. 288.1 D & B03.28 & 18 & T45 \\
\hline PSI inv. D & 94.10 & inv.provv. 75.12 D & B03.21 & 28 & \\
\hline PSI inv. D & 94.11 & inv. s.n. (b) D & B03.31 & 31 & \\
\hline PSI inv. D & 94.12 & inv.provv. 75.15 D & B03.29 & 29 & \\
\hline PSI inv. D & 94.13 & inv.provv. 75.19 D & B03.30 & 30 & \\
\hline PSI inv. D & 94.14 & inv.provv. 288.2 D & & 32 & \\
\hline PSI inv. D & 94.15 & inv.provv. 288.3 D & & 33 & \\
\hline
\end{tabular}

\section{Descriptions and transcriptions of the individual fragments}

The curiosity value of an astronomical almanac of such great extent and yet in such an incomplete state might appear scarcely to justify the effort of working out the original positions of scraps on which we seldom find more than ruled lines and occasionally a repetitive series of month names. However, leaving aside its equivocal testimony as a witness to the activity of an astronomical-astrological atelier in Roman Tebtunis, the reconstruction has the potential to significantly enhance the usefulness of the roll as a copy of the Book of Thoth, by supplying a more precise frame of reference for its disparate parts. ${ }^{31} \mathrm{We}$ therefore provide descriptions and concordances of all known fragments of the roll, including the many that have only ruling (or even no text at all) on their rectos, in the order of their original positions, with unplaced fragments at the end. The accompanying diagram (Fig. 3) shows the approximate positions of the placed fragments (recto view), with the almanac rulings drawn as fine gray lines and the attested or estimated beginnings of the Book of Thoth text columns as thicker and paler gray lines.

\footnotetext{
${ }^{31}$ For example, from it one can obtain an estimate of the extent of a major lacuna, mentioned below in the description of fragment 3 .
} 

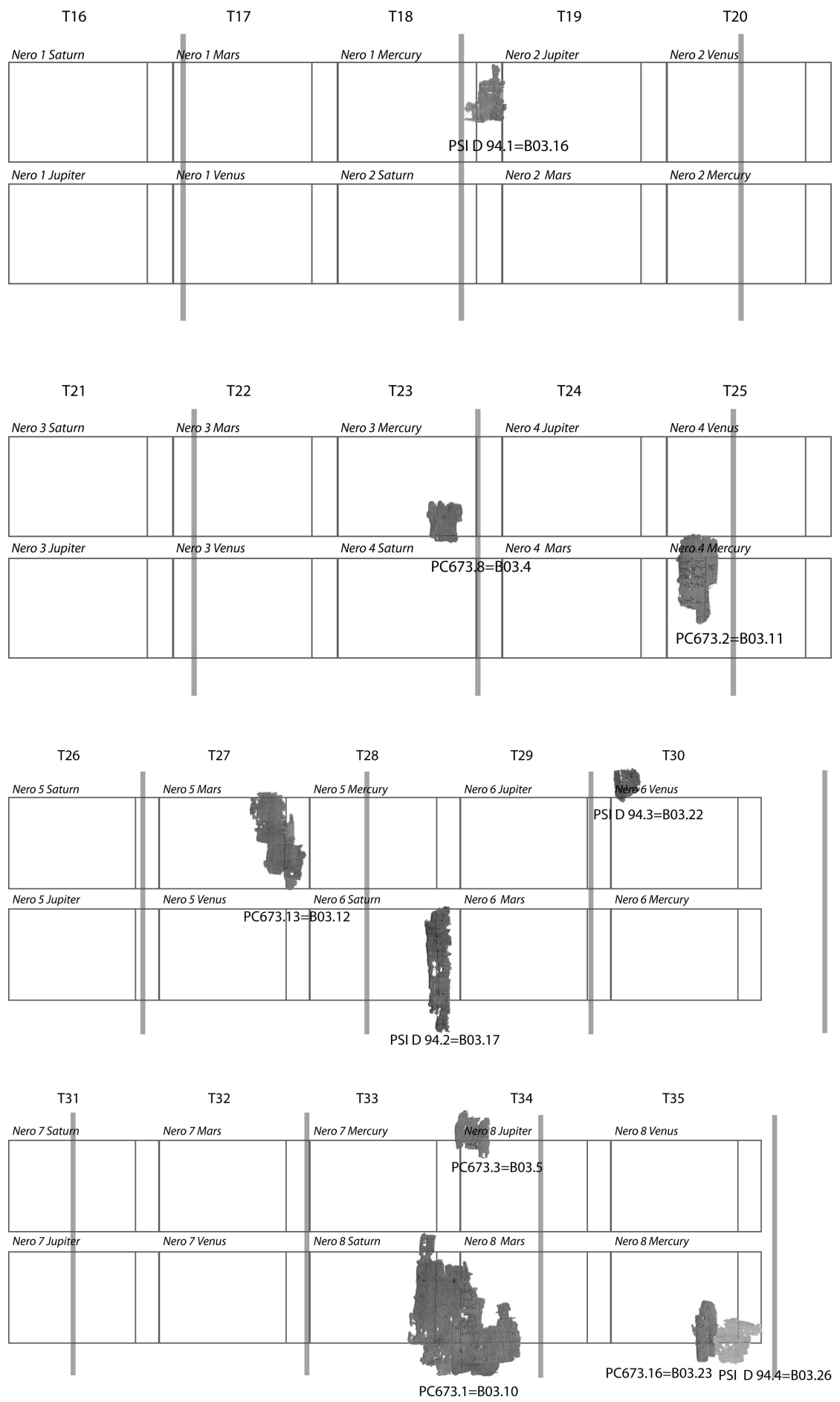

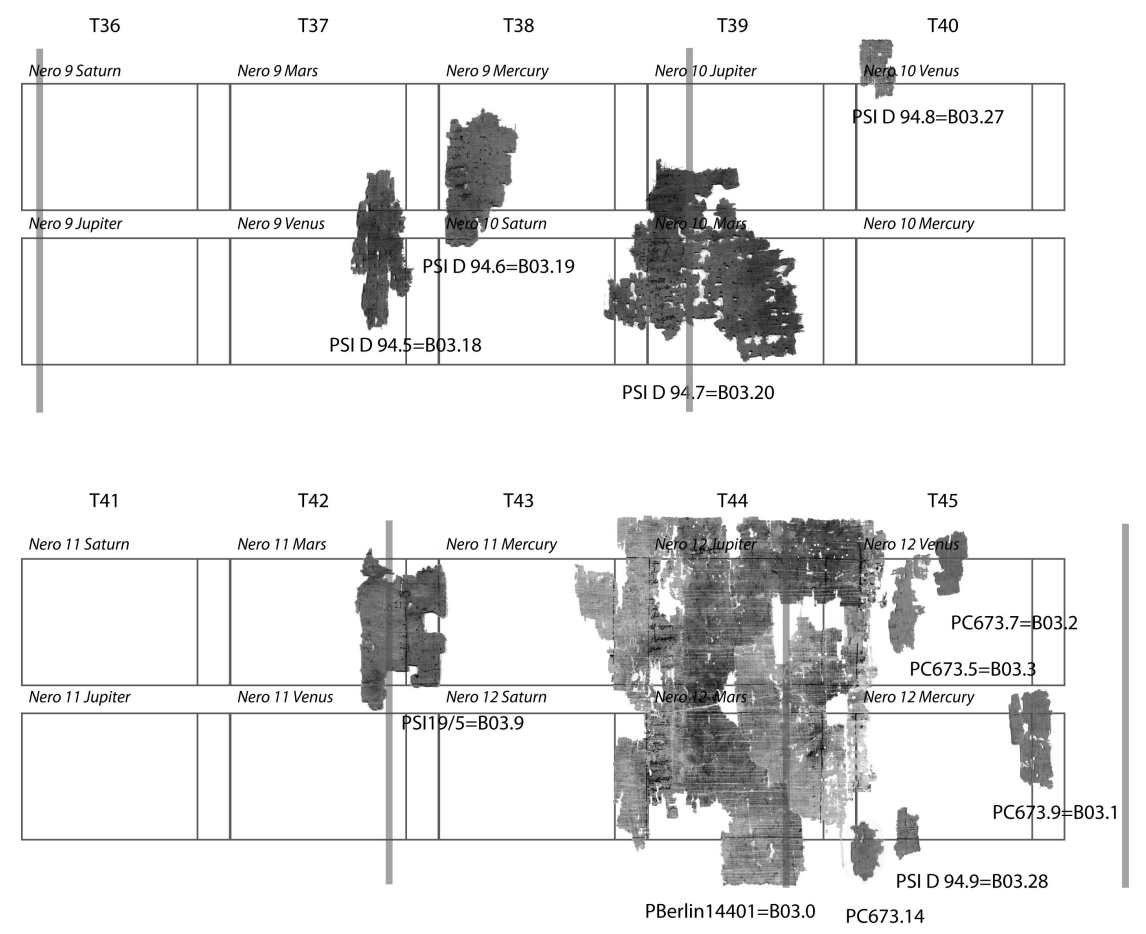

Fig. 3. Placement of fragments of the almanac

1. PSI inv. 94 Fr. 1 (B03.16 = F01 7ff.), 3.8 x 5.2. Two vertical rulings approximately $2.4 \mathrm{~cm}$ apart, identifiable as $\mathrm{v} 2$ and $\mathrm{v} 1$. No text. The placement towards the top of T18-T19 is estimated on the basis of the Book of Thoth parallel and extrapolation backwards from the parallels for fragments 2 and 3. A slightly lower position between $\mathrm{h} 1$ and $\mathrm{h} 2$ would be admissible.

2. P.Carlsb. 673 Fr. 8 (B03.4 = B06 3/3ff.), 3.0 x 5.0. Horizontal ruling, no text. The placement in T23, such that the ruling is $\mathrm{h} 2$, is determined by the Book of Thoth parallel and extrapolation backwards from the parallel for fragment 3 . The horizontal position is not exactly determined.

3. P.Carlsb. 673 Fr. 2 (B03.11 = B06 4/5ff.), 3.8 x 8.0. Horizontal rulings v2, $\mathrm{v} 3$, and $\mathrm{v}^{*}$ (at least three, faint, not represented in our transcription), two vertical rulings $\mathrm{v}^{*}$ (1.8 cm apart), planet name (Mercury) and astronomical data fitting Mercury for Nero 4 (Hand 1). The placement is established by the astronomical data. The horizontal rulings require a year for which Mercury occupies a lower almanac block. There is a discontinuity in the reconstructed Book of Thoth text between the parallel to this fragment and the parallels to the next preserved fragment in the roll, fragment 4. 
$\left.{ }^{`} \mathrm{E}\right] \rho \mu \hat{n} \varsigma$

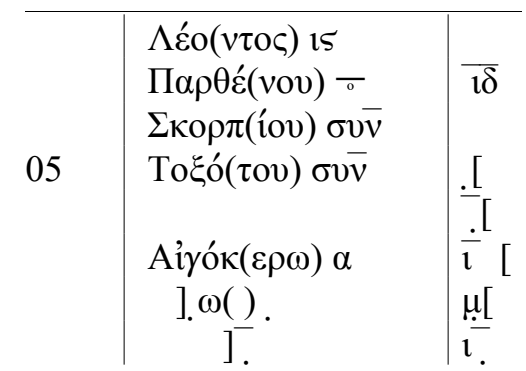

5-6 бטv̄: on this abbreviation see note 30 above traces at mid height

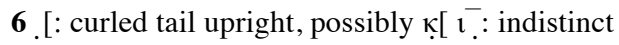

Dating P.Carlsb. 673.2

The fragment is part of the table for Mercury for an unidentified year according to the unreformed Egyptian calendar. The column of month names is lost but reconstructible; unfortunately the column of day numbers is also entirely missing. We can provisionally reconstruct the table as follows:

$\begin{array}{lllll}\text { Thoth } & \text { day xx } & \text { Leo } 16^{\circ} & \text { blank } & \\ \text { Phaophi } & \text { day xx } & \text { Virgo } 0^{\circ} & 14 & \text { [Libra } 0^{\circ} ? \text { ] } \\ \text { Hathyr } & \text { day xx } & \text { Scorpio } 0^{\circ} & \text { blank } & \\ \text { Choeac } & \text { day xx } & \text { Sagittarius } 0^{\circ} 6 ? & \text { [unidentified event] } \\ \text { Tybi } & \text { day } x x & \text { blank } & \text { xx } & \text { [unidentified event] } \\ \text { Mecheir } & \text { day xx } & \text { Capricorn } 1^{\circ} 1 \mathrm{x} & \text { [unidentified event] } \\ \text { Phamenoth } & \text { day xx } & ? ? & ? ? & \\ \text { Pharmouthi } & \text { day xx } & ? ? & 1 \mathrm{x} & \text { [unidentified event] }\end{array}$

The first facts we can use are that Mercury was stated to be at Leo $16^{\circ}$ on some date during Thoth, that it did not enter or leave this sign (longitude $120^{\circ}-150^{\circ}$ ) during Thoth, and that it entered Virgo and then Libra during Phaophi. We further know that we are dealing with an even-numbered regnal year, since Mercury is in the lower almanac block, and that the Book of Thoth parallel precedes the parallel for fragment 4 (which is in T27, Nero 5) by an uncertain number of lines, but surely not enough to push fragment 3 into a year before the reign of Nero, i.e. left of T16. Thus our only real choices are Nero 2 and Nero 4. We also have to consider whether the calendar according to which the almanac is structured is the civil Egyptian calendar (with Thoth $1=$ August 29 or 30) or the unreformed ( $\kappa \alpha \tau$ ' à $\rho \alpha$ áovc) Egyptian calendar, which was often used in astronomical tables because of the computational convenience of its constant years. In the years under consi- 
deration, the old calendar was running twenty days in advance of the civil calendar.

If we compute Mercury's longitudes during Nero 2 and 4 according to both calendars, we find that only Nero 4 according to the old calendar yields an acceptable match to the data in the papyrus (Fig. 2). ${ }^{32}$ Using the recomputations from modern theory, we can partially reconstruct the statements in the almanac. For some date in Thoth, the papyrus gives a longitude Leo $16^{\circ}$, which could either be the longitude on Thoth 1 or that of the planet's morning station. The entry into Virgo must have been very close to the first of the Phaophi, if not on the very day; whether it is significant that the papyrus explicitly gives a longitude of $0^{\circ}$ in the sign instead of the sign-entry indication ovv is not clear. The event on Phaophi 14 must have been the entry into Libra. The entry into Scorpio was placed during Hathyr as expected, but that into Sagittarius was placed in Choeac, thus a little later than according to modern theory. The event occurring on Choeac 6 (?) would probably have been the evening station. The event in Tybi may have been the morning station (but we do not understand why the preserved part of this line begins with a blank space), while entry into Capricorn and Aquarius followed in Mecheir, and into Pisces in Phamenoth. Pharmouthi had at least two listed events, likely including at least one of the stations.

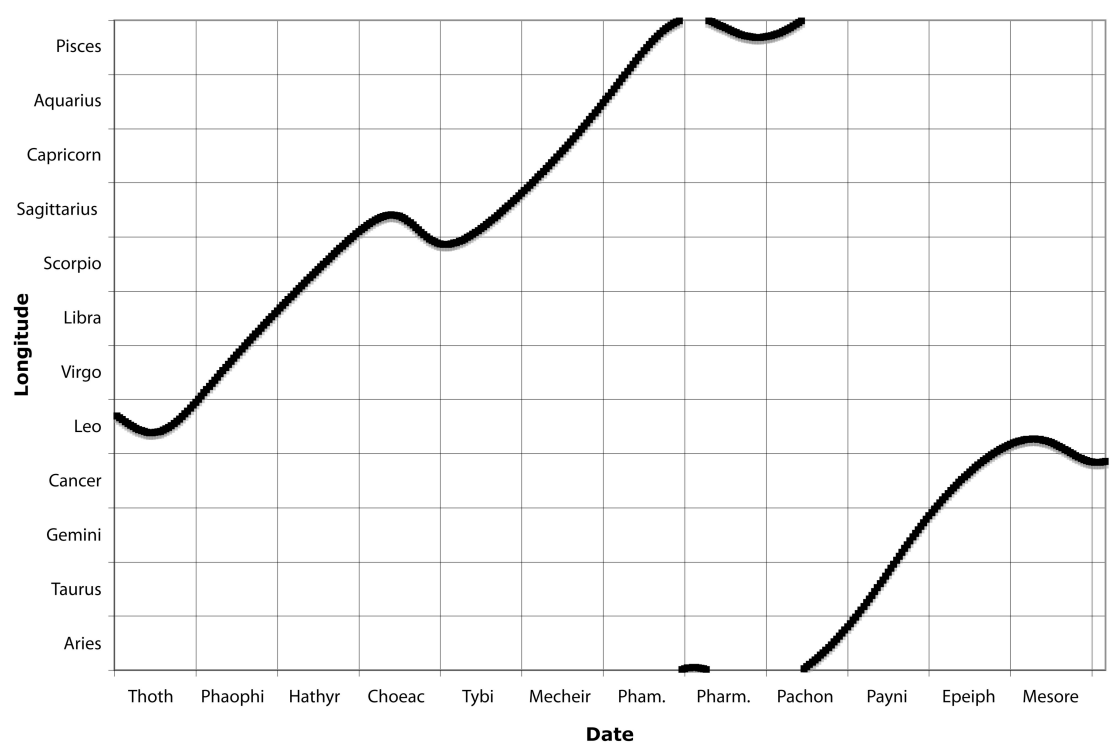

Fig. 4. Longitudes of Mercury during Nero 4, old Egyptian calendar, according to modern theory

32 Computations according to modern theory are from the JPL Horizons ephemeris, http://ssd.jpl.nasa.gov/?horizons. The 'Song of Horus' almanac also follows the old Egyptian calendar; see Manfredi and Neugebauer, 'Greek Planetary Tables' (note 22 above), 103. 
4. P.Carlsb. 673 Fr. 13 (B03.12 = ca. V01 1/19ff.), 5.6 x 9.5. Horizontal ruling (h1) and vertical ruling (v2), no text. The placement is determined by the Book of Thoth parallel and extrapolation from the parallels for fragments 5 and 6 .

5. PSI inv. D 94 Fr. 2 (B03.17 = V04 12ff.), 2.6 x 12.2. Horizontal rulings h3 and $\mathrm{h} 4$, with $3.2 \mathrm{~cm}$ lower margin (too tall to be the gap between $\mathrm{h} 2$ and $\mathrm{h} 3$ ), vertical ruling v2, no text. Placement determined by the Book of Thoth parallel and extrapolation from the parallel for fragment 6 .

6. PSI inv. D 94 Fr. 3 (B03.22 = V04 21ff. = C04.1 11ff.), 2.6 x 3.4. Horizontal ruling h1 with $2.9 \mathrm{~cm}$ upper margin (too tall to be the gap between $\mathrm{h} 2$ and $\mathrm{h} 3$ ), and year number 6 (Hand 1). This year number would only appear in the header of an upper almanac block in T29 or T30. A placement in T29 would force the three text columns of Book of Thoth text between fragments 3 and 6 to be implausibly narrow (average about $16 \mathrm{~cm}$ instead of $20 \mathrm{~cm}$ ).

$$
] \varsigma\llcorner[
$$

7. P.Carlsb. 673 Fr. 1 (B03.10= B02 3/15ff.), 10.9 x 13.8. Horizontal rulings $\mathrm{h} 3$ and $\mathrm{h} 4$ with $3.2 \mathrm{~cm}$ lower margin, vertical rulings $\mathrm{v} 2$ and $\mathrm{v} 1$, and month names (Hand 3). Placement determined by the Book of Thoth parallel and extrapolation from the parallel for fragment 6 .

05

\begin{tabular}{|c|c|}
\hline & 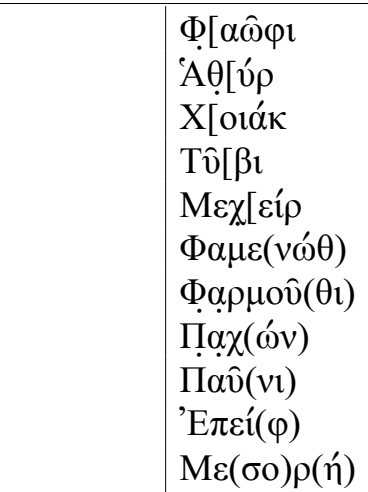 \\
\hline
\end{tabular}

8. P.Carlsb. 673 Fr. 3 (B03.5 = B02 3/4ff.), 3.4 x 4.7. Horizontal ruling h1 with $3.0 \mathrm{~cm}$ upper margin (too tall to be the gap between $\mathrm{h} 2$ and $\mathrm{h} 3$ ), vertical ruling $\mathrm{v} 1$, year number 8 (Hand 1), months (Hand 2). This year number would only appear above an upper almanac block in T34 or T35. The Book of Thoth parallel shows that the fragment must have been directly above the middle of fragment 7 . 
] $\eta\llcorner[$

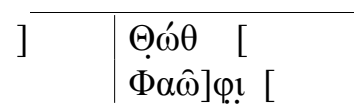

9-10. P.Carlsb. 673 Fr. $16+$ PSI inv. D 94 Fr. 4 (B03.23 + B03.26 = B02 $5 / 15$ ff.), $2.5 \times 5.9+4.8 \times 4.5$ (aggregate $7.0 \times 6.0$ ). Horizontal ruling h4 with $2.0 \mathrm{~cm}$ lower margin, vertical ruling v2, no text. The join (confirmed by matches of recto fibers) and placement are determined by the Book of Thoth parallel in relation to the parallels for the preceding and following fragments.

11. PSI inv. D 94 Fr. 5 (B03.18 = B02 8/12ff.), 4.4 x 11.2. Horizontal rulings h2, h3; vertical ruling v2; no text. Placement determined by the Book of Thoth parallel in relation to those of fragments 12 and 13.

12. PSI inv. D 94 Fr. 6 (B03.19 = B02 8/6ff.), 5.1 x 9.6. Horizontal ruling h2, $\mathrm{h} 3$; year number 10 (Hand 1), months (Hand 2). The Book of Thoth parallels show that this fragment was situated between fragments 11 and 13, sharing some of the same verses with both fragments. The two lower almanac blocks whose headers are partly preserved in fragments 12 and 13, both with year 10, have to have been either in T38-T39 or T39-T40. We can effectively rule out the second possibility, first because the traces of the planet name in fragment 13 fit the name of Mars but not that of Mercury, and secondly because with fragment 13 in T40, the exactly placed fragment 14 would be directly above fragment 13 in such a way that the bits of three consecutive lines of Demotic text on fragment 14 would be right in the gap between the two text columns partially preserved in fragment 13 .

\begin{tabular}{|c|c|}
\hline & [A $A \theta u$ \\
\hline & {$[\mathrm{X}] \mathrm{ọ}\left[{ }^{\prime} \alpha \dot{\alpha}\right] \kappa$} \\
\hline & Tộ̣ı \\
\hline & {$[\mathrm{M}] \xi \chi \xi(\hat{\imath} \rho)$} \\
\hline 05 & {$[\Phi] \alpha \mu \varepsilon(v \omega \dot{\theta} \theta)$} \\
\hline & $\Phi \alpha \rho \mu[0] \widehat{v}(\theta i)$ \\
\hline & 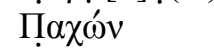 \\
\hline & 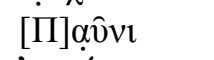 \\
\hline & 'Ел⿻上丨 \\
\hline 10 & [M] \\
\hline & $1\llcorner[$ \\
\hline & 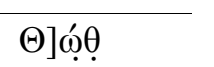 \\
\hline
\end{tabular}

13. PSI inv. D 94 Fr. 7 (B03.20 = B02 10/4ff.), 13.9 x 14.3. Horizontal rulings h2, h3; vertical rulings v2, v1; year number 10 (Hand 1); months (Hand 2). For the basis of placement see fragment 12 . 
05

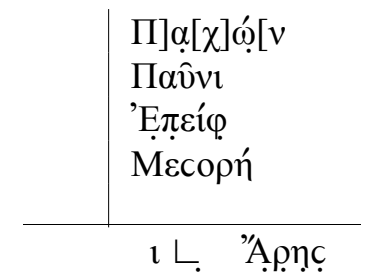

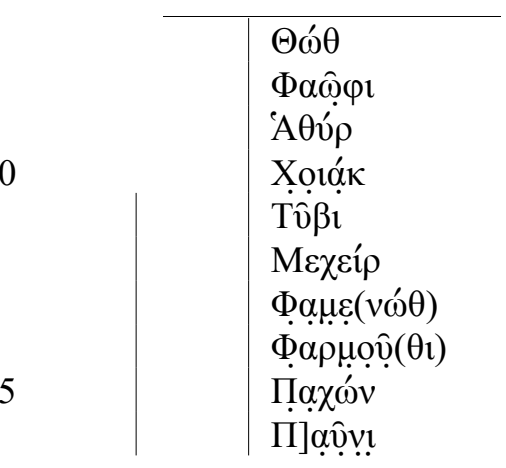

14. PSI inv. D 94 Fr. $8\left(B 03.27=?^{33}\right), 2.7 \times 4.2$. Horizontal ruling h1 with 3 $\mathrm{cm}$ upper margin, year number 10 and planet name Venus (Hand 1). The information on the recto gives an exact placement at the top of T40.

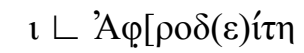

15. PSI inv. D 19/5 (B03.9 = B02 ca. 13/8ff.), 6.3 x 11.2. Horizontal ruling h2, vertical rulings v2 and v1; no text. For placement see fragment 16.

16. P.Berl. 14401 (B03.0 = B02 ca. 13/5ff.), 22.5 x 26.4. Horizontal ruling h1, h2, h3, h4; vertical ruling v2, v1, v2, v1 (two pairs); year number 12 and planet names Jupiter and Mars (Hand 1); months (Hand 2). The year number and planet names for the central pair of almanac blocks fixes their location in T44. The two columns of Book of Thoth text establish the placements of fragments 15 and 1721 which which they share verses. The transcription incorporates readings from fragments 17 and 19 .

\begin{tabular}{|c|c|c|}
\hline & {$[1] \beta\llcorner Z \varepsilon u ́ c$} & 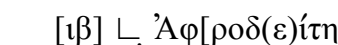 \\
\hline 05 & 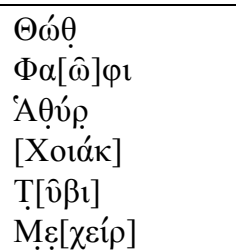 & 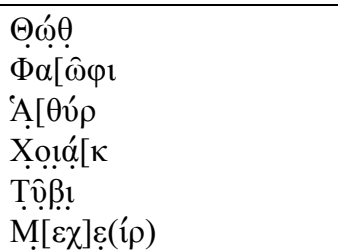 \\
\hline
\end{tabular}

${ }^{33}$ Should parallel B02 ca. 9/12ff., but a clear correspondence is lacking. 


\begin{tabular}{|c|c|}
\hline 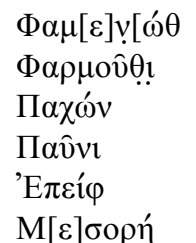 & 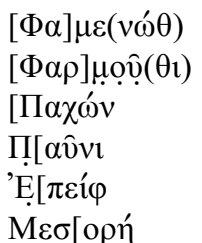 \\
\hline
\end{tabular}

15

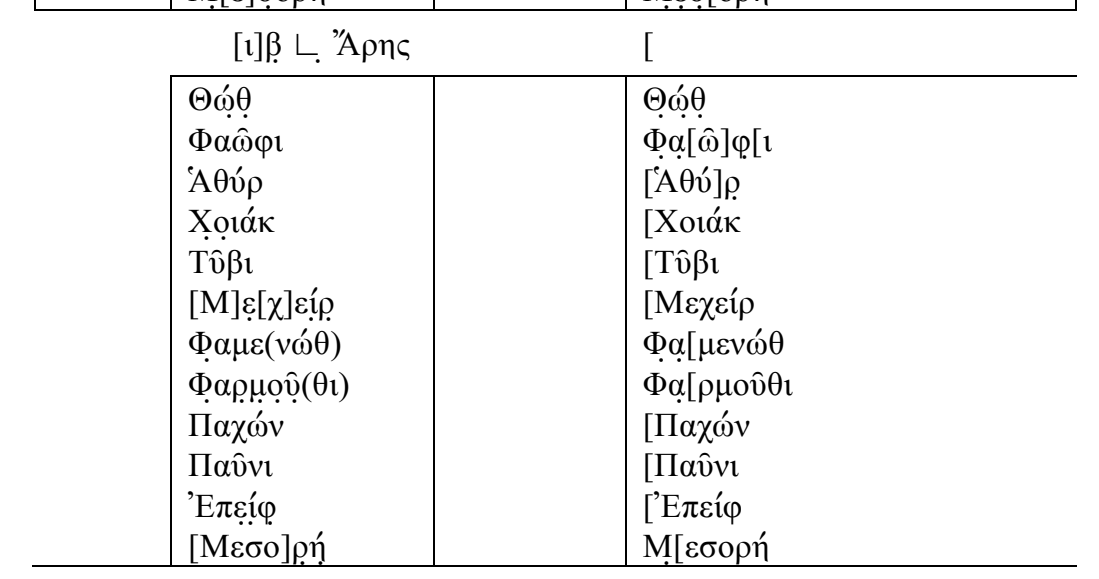

17. P.Carlsb. 673 Fr. 14 (B03.14 = B02 15/3f.), 2.3 x 4.1. Horizontal ruling h4 with $2.9 \mathrm{~cm}$ lower margin; trace of vertical ruling v1; trace of month name. See fragment 16 for placement and transcription.

18. PSI inv. D 94 Fr. 9 (B03.28 = B02 15/2ff.), $1.8 \times$ 3.7. Horizontal ruling h4 with $1.5 \mathrm{~cm}$ lower margin; no text. See fragment 16 for placement.

19. P.Carlsb. 673 Fr. 5 (B03.3 = B02 ca. 14/5), 3.3 x 6.9. Horizontal ruling h1; traces of year and planet name (Hand 1); months (Hand 2). See fragment 16 for placement and transcription.

20. P.Carlsb. 673 Fr. 7 (B03.2 = B02 ca. 14/4), 2.4 x 4.5. Horizontal ruling h1 with $1.9 \mathrm{~cm}$ upper margin; no text. See fragment 16 for placement.

21. P.Carlsb. 673 Fr. 9 (B03.1 = B02 ca. 14/12), 3.2 x 6.9. Horizontal stroke h3; vertical stroke v2; no text. See fragment 16 for placement.

Unplaced fragments from the Book of Thoth roll (B03)

22. P.Carlsb. 673 Fr. 4 (B03.13), 3.3 x 5.5. Horizontal ruling h1 with $2.3 \mathrm{~cm}$ upper margin (too tall to be the space between h2 and h3); planet name Venus (Hand 1); indeterminate traces above planet name. The fragment must belong to an even-numbered regnal year. 


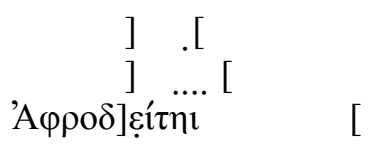

23. P. Carlsb. 673 Fr. 6 (B03.15), 3.6 x 8.8. Traces of planetary data (Hand 1); no ruling.

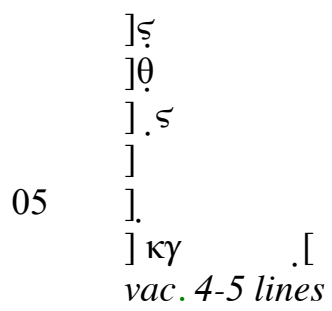

24. P.Carlsb. 673 Fr. 10 (B03.6), $2.5 \times$ x.5. Horizontal ruling h4 with $2.9 \mathrm{~cm}$ lower margin; vertical ruling $\mathrm{v} 2$; no text.

25. P.Carlsb. 673 Fr. $11+12$ (B03.7+8), 2.7 x 4.5 and 1.6 x 5.1 (aggregate $4.1 \times$ 5.4). Horizontal stroke $\mathrm{h} 1$ or $\mathrm{h} 4$ with $2.3 \mathrm{~cm}$ upper margin; vertical ruling v2 (probably, since there is no trace of month names to its right); no text.

26. P.Carlsb. 673 Fr. 15 (B03.24), 1.8 x 2.2. Blank.

27. P.Carlsb. 673 Fr. 17 (B03.25), $5.0 \times$ 4.4. Horizontal stroke h4 with $2.1 \mathrm{~cm}$ lower margin and $2.3 \mathrm{~cm}$ blank space above. The Demotic verse ends on the verso appear to be from the bottom of a text column.

28. PSI inv. D 94 Fr. 10 (B03.21), 5.1 x 9.6. Horizontal ruling h1; vertical rulings $\mathrm{v} 2$ and $\mathrm{v} 1$; months (Hand 2).

05

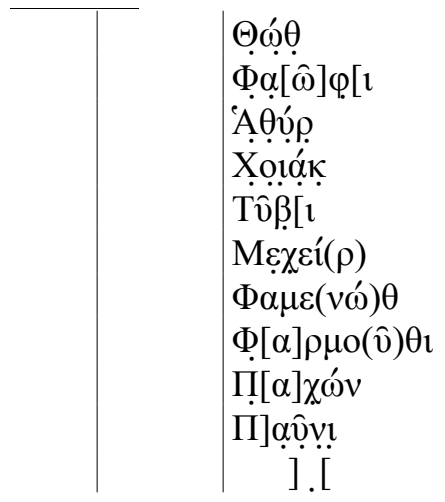

29. PSI inv. D 94 Fr. 12 (B03.29), $2.7 \times$ 2.5. Horizontal ruling h1 or h3; h* (at least 3 , faint); v2 or $\mathrm{v}^{*}$; planetary data (Hand 1). 


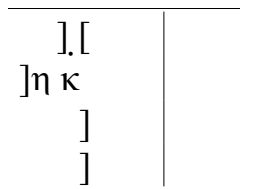

30. PSI inv. D 94 Fr. 13 (B03.30), 1.1 x 2.2. Vertical ruling v1; months (Hand 2).

\begin{tabular}{|c|c|}
\hline & 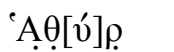 \\
\hline & X̣[o]!ִ̣̣́k \\
\hline & Тิ์ $\beta !$ \\
\hline 05 & 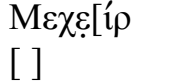 \\
\hline & $\Phi \alpha[\rho \mu \mathrm{ov} \theta \mathrm{\imath}$ \\
\hline
\end{tabular}

31. PSI inv. D 94 Fr. 11 (B03.31), 4.2 x 5.5. Horizontal rulings h2 and h3; no text.

32. PSI inv. D 94 Fr. $14,1.2 \times 2.3$. Horizontal ruling h1 or h3 with $1.6 \mathrm{~cm}$ vacant space above; vertical ruling v1; month name (Hand 2).

$$
\mid \Theta[\omega ́ \theta
$$

33. PSI inv. D 94 Fr. 15, 1.8 x 2.7. Horizontal ruling h1 or h3; planet name (Mars or Venus) (Hand 1); trace of month name (Hand 2?).

$$
\begin{aligned}
& \text { ] ᄂ. 'A[ }
\end{aligned}
$$

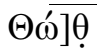

\section{V.P.Carlsb. 726, lunar template (Plate XX)}

The fragment, measuring $6 \times 5 \mathrm{~cm}$, is written across the fibres in a black tabular framework. On the recto runs a Greek documentary text (unpublished), paleographically assignable to the first or second century AD. The papyrus comes in all likelihood from Tebtunis. 


\section{Transcription}

\begin{tabular}{|c|c|c|c|c|c|}
\hline \multirow[t]{4}{*}{$i$} & ii & iii & \multirow[t]{2}{*}{ iv } & \multirow{2}{*}{$\begin{array}{l}V \\
\mid] 1 \delta[\end{array}$} & $v i$ \\
\hline & & & & & $\rho[$ \\
\hline & c]Q⿱亠凶禸 & . & & $1 \delta$ & $\rho[$ \\
\hline & ]$\tau \eta$ & $\lambda s$ & $\rho \kappa \varepsilon$ & $1 \delta$ & $c \zeta[$ \\
\hline ] $1 \beta$ & $\tau \kappa \alpha$ & $y$ & & $1 \delta$ & [ \\
\hline ] $1 \beta$ & $\tau \lambda \gamma$ & $\lambda \varepsilon$ & & $![\delta$ & \\
\hline ] & $\tau \mu \varepsilon$ & $\mu \varsigma$ & & {[} & \\
\hline
\end{tabular}

col. ii 5 probably $\alpha$ corrected to $\gamma \quad$ col. iii 2 ]. [: upper extremity of a diagonal stroke descending from left to right, then a dot at mid height $\mathbf{5}$ probably $\gamma$ corrected to $\varepsilon$

\section{Translation}

For the restoration of column [0] missing digits in other columns see the commentary below.

\begin{tabular}{|c|c|c|c|c|c|c|}
\hline \multirow[t]{3}{*}{ [0] } & $i$ & $i i$ & $i i i$ & $i v$ & $v$ & $v i$ \\
\hline & 13] & \multicolumn{3}{|l|}{$[2 x x]$} & 14 & $1[x x$ \\
\hline & 13] & [2]95 & $x x$ & & 14 & $1[x x$ \\
\hline [105] & {$[x x]$} & 308 & 36 & 125 & 14 & $2[x x$ \\
\hline & 12 & 321 & 13 & & 14 & {$[2 x x$} \\
\hline & 12 & 333 & 35 & & $1[4$ & \\
\hline & 12 & 345 & 46 & & {$[14$} & \\
\hline
\end{tabular}

The presence of a column containing index numbers at intervals of 5 marks this small but interesting fragment as part of a template (see P.Carlsb. 141 above). The quantity in columns ii-iii increases line-to-line by between 12 and 13, a rate of progress possible for the Moon but not for any other heavenly body. Provisionally, 
we may hypothesize that the structure of the template consists of the index column counting days since epoch, enclosed by double vertical rulings (here, col. iv); a column containing the current daily progress in longitude, truncated to integer degrees (cols. i and v); and the longitudinal progress since epoch in degrees and minutes (cols. ii-iii and vi).

Two templates based on different sets of parameters for the Moon's motion are currently known and fully reconstructible from Roman period papyri: one, closely adhering to a Babylonian arithmetical 'linear zigzag' model transmitted into Greek astronomy in the Hellenistic period, is attested in a papyrus from Tebtunis $;{ }^{34}$ the other, based on more refined parameters, is part of the widespread Standard Lunar Scheme known from numerous papyri of varied provenance. ${ }^{35}$ It is an easy matter to locate the parts of these templates that correspond to the present fragment. For purposes of comparison, we present the corresponding portions of the Standard Scheme template according to the fragment's tabular structure:

\begin{tabular}{|c|c|c|c|c|c|c|}
\hline \multirow{7}{*}{105} & 13 & 281 & 25 & & 14 & $\mid 177$ \\
\hline & 13 & 294 & 39 & & 14 & 192 \\
\hline & 13 & 307 & 41 & 125 & 14 & 207 \\
\hline & 12 & 320 & 31 & & 14 & 221 \\
\hline & 12 & 333 & 7 & & 14 & 235 \\
\hline & 12 & 345 & 30 & & 14 & 249 \\
\hline & 12 & 357 & 41 & & 13 & 263 \\
\hline
\end{tabular}

The comparison confirms our provisional assumptions about the significance of the columns, and establishes the day numbers to which cols. i-iii pertain, from which we learn that the table was laid out in 20 rows, not counting headings. The complete template would have covered a cycle of either 248 or 303 days (i.e. 9 or 11 anomalistic periods of the Moon).

The values of the lunar progress since epoch attested in our papyrus do not exactly match those of the Standard Scheme template, but a pattern linking them is apparent: the value corresponding to day $\mathrm{d}$ in the papyrus seems to be consistently $11^{\circ} 54^{\prime}$ or $11^{\circ} 55^{\prime}$ less than the value corresponding to the next day, day $\mathrm{d}+1$, in the Standard Scheme template. The template was supposed to be generated by computing a cycle of 248 or 303 values of a so-called linear zigzag function representing the daily progress in longitude, starting with the value corresponding to the day following a day of minimum progress, and adding successive values of this function to an initial value equal to the minimum daily progress, which corresponded to 'day 1', the day following the epoch date. Whoever prepared this template, however, started with the correct value for day 1, but by

\footnotetext{
34 A. Jones, 'More Astronomical Tables' (note 9 above), text 7 on 216-220.

35 A. Jones, 'Studies in the Astronomy of the Roman Period. I. The Standard Lunar Scheme', Centaurus 39, 1997, 1-36; Jones, Astronomical Papyri from Oxyrhynchus (note 12 above), v. 1, $18-19$.
} 
mistake proceeded to add successive values of the zigzag function starting with the value that was supposed to be added to day 2's total, not day 1's. In the resulting template all the cycles of lunar velocity were thus one day in advance. The effects of this misalignment would have been periodic, with maximum discrepancies from the correct Standard Scheme template, amounting to nearly $3^{\circ}$ in excess, near the halfway stages of each anomalistic period. 


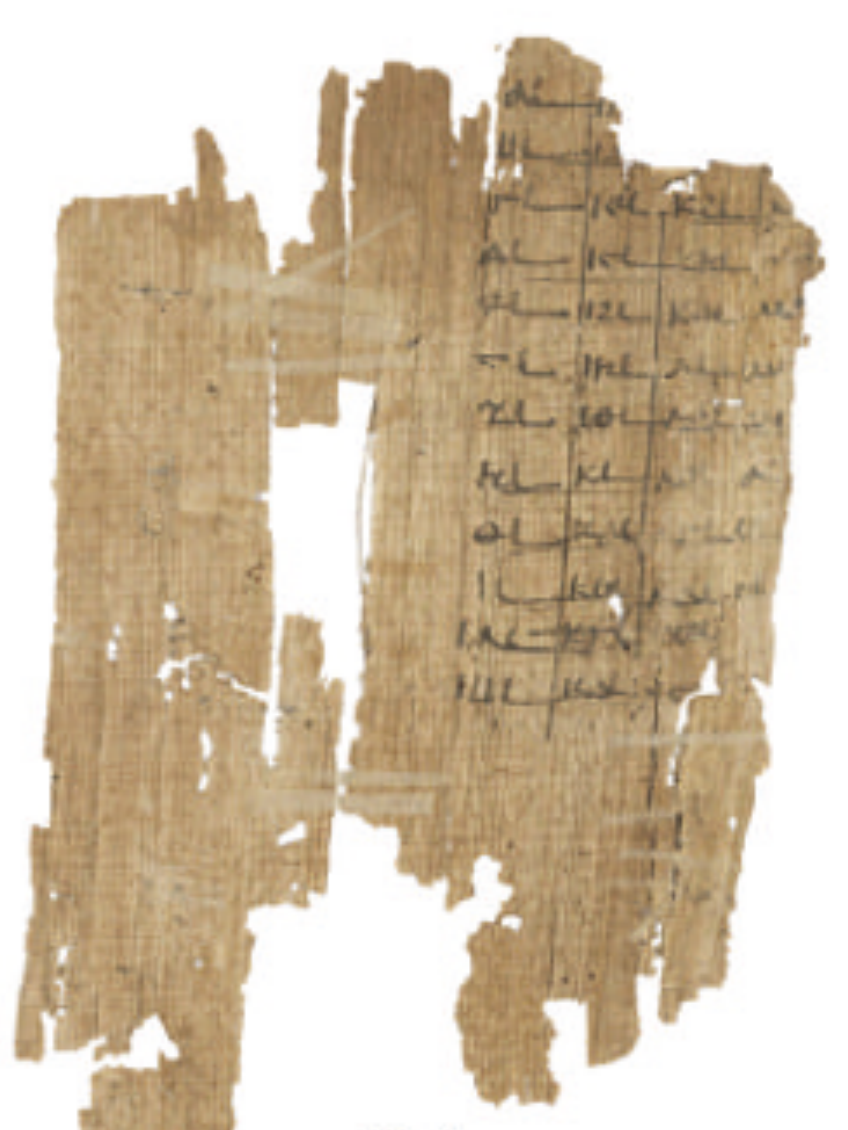

Fr. 1

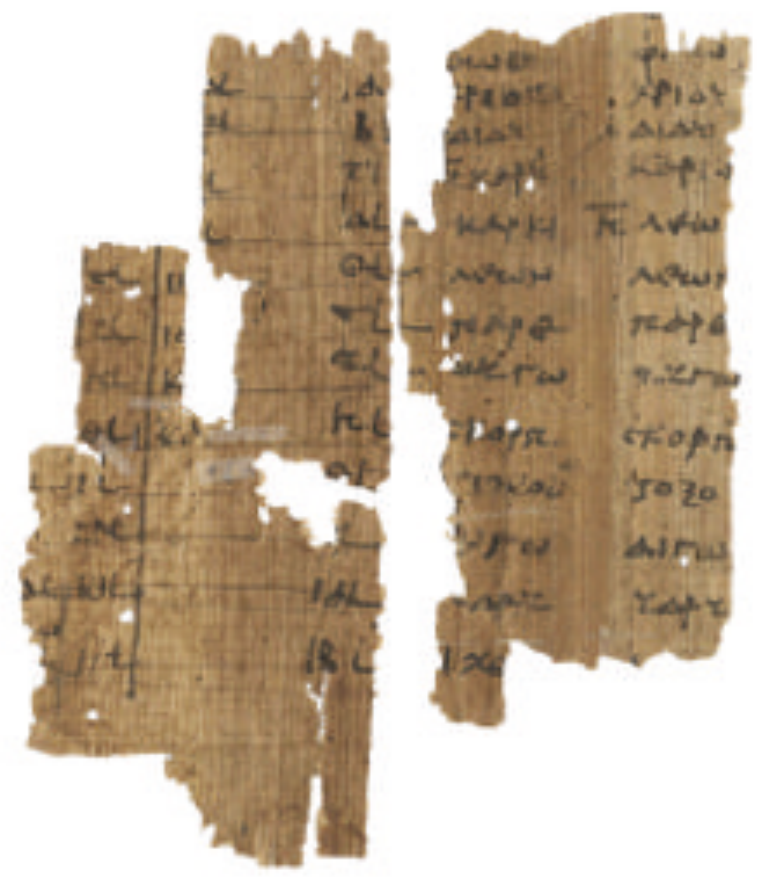

Fr. 2

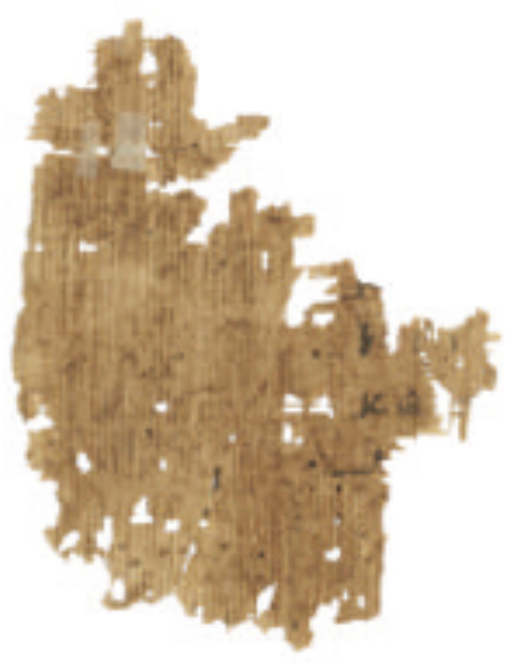

Fr. 5

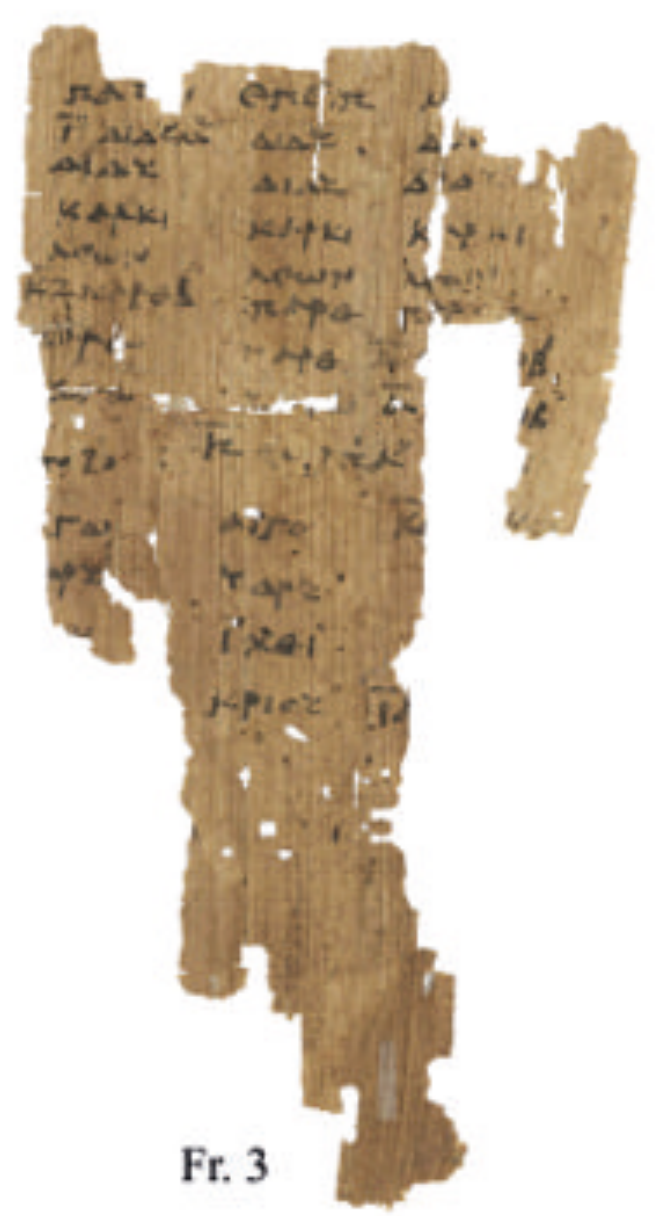




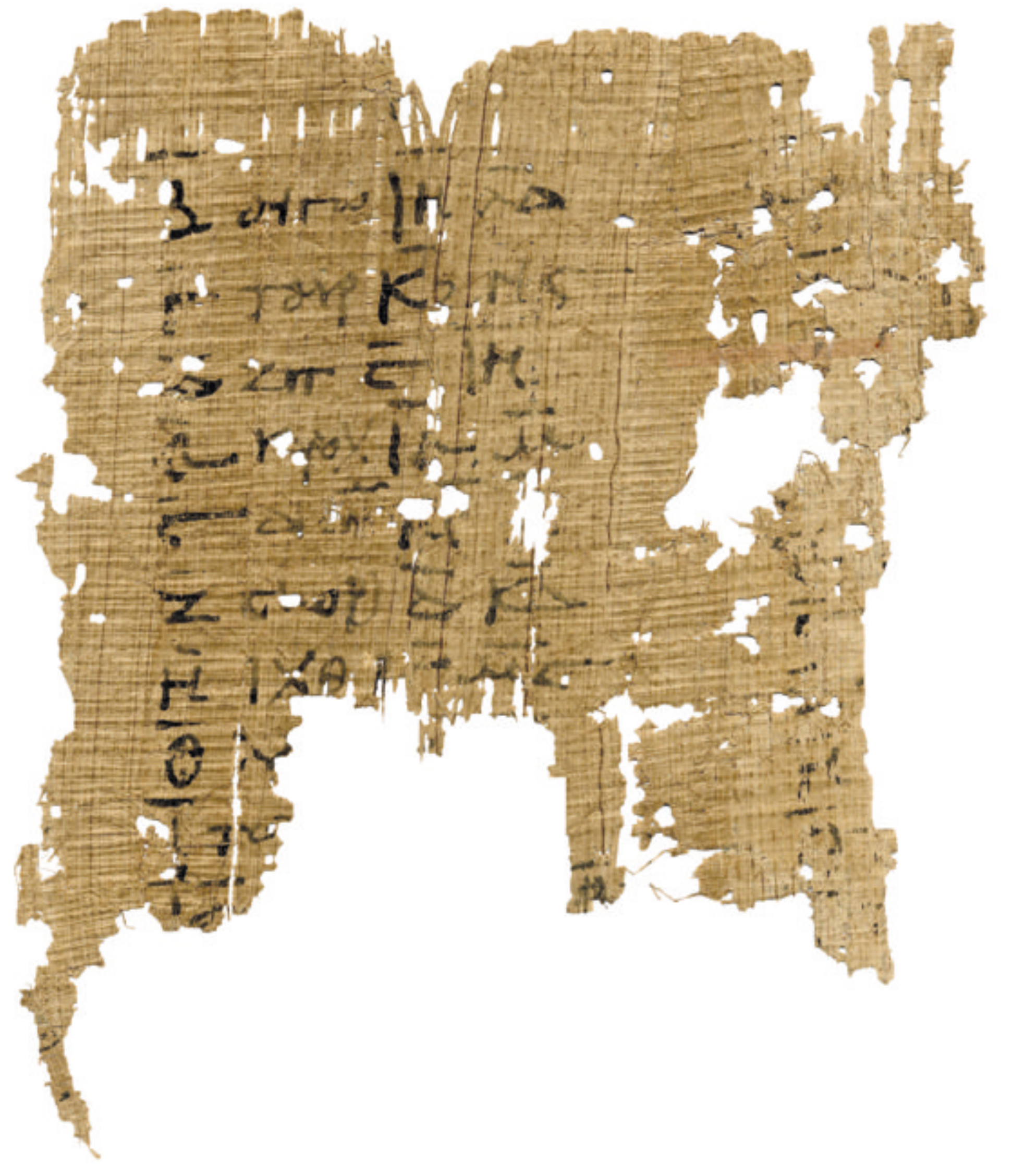




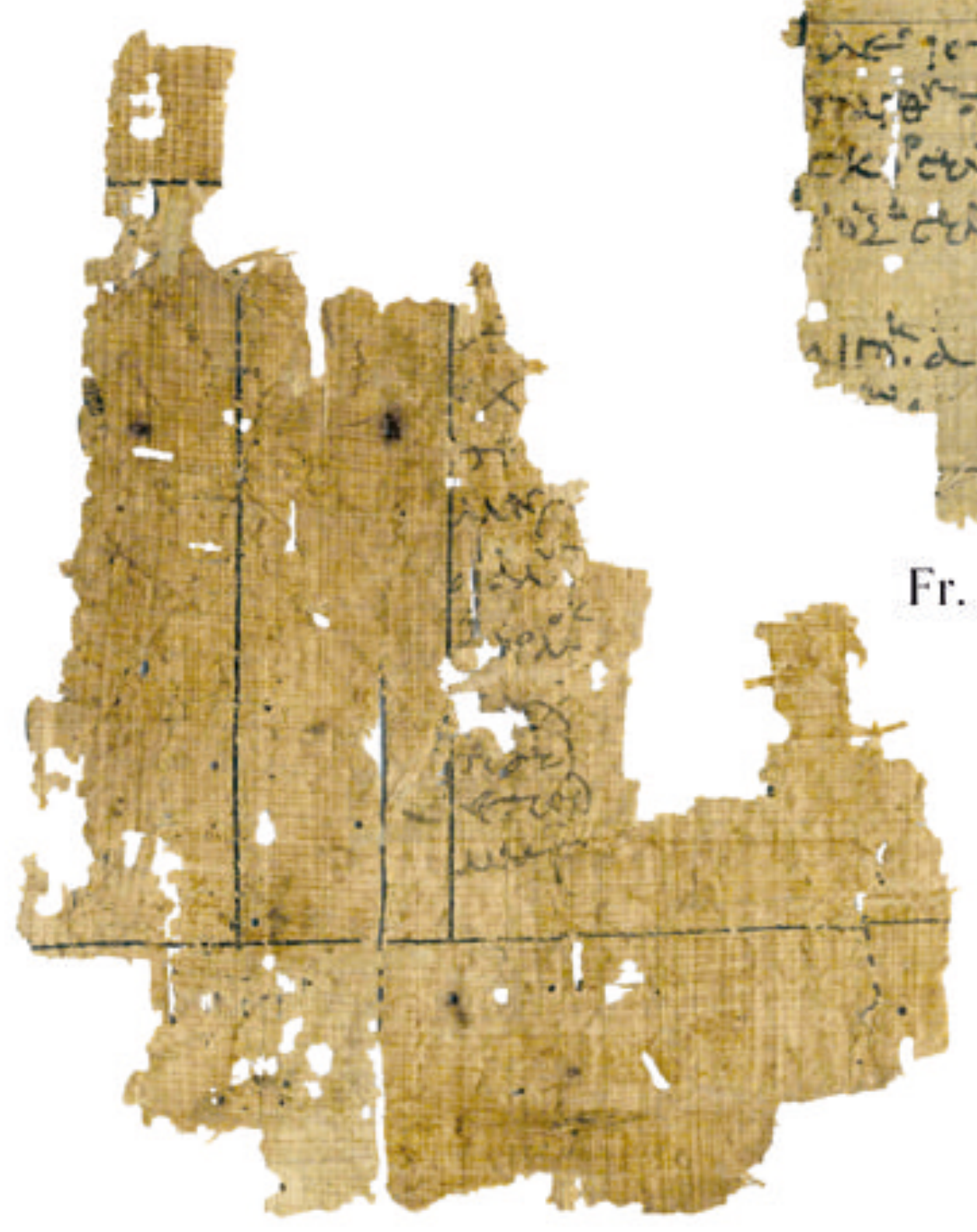

Fr. I

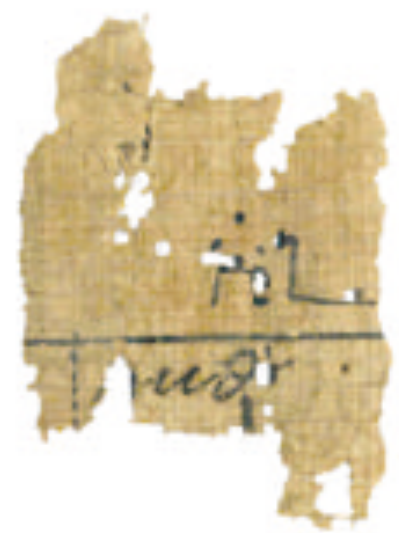

Fr. 3

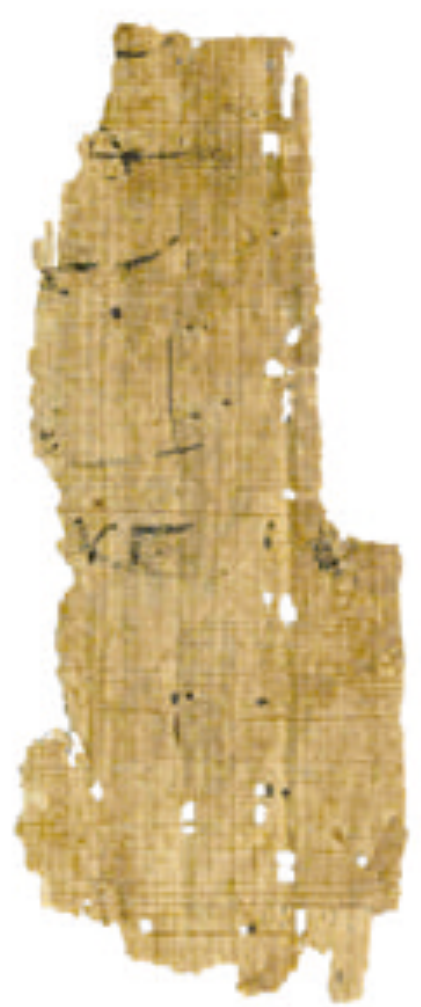

Fr. 6

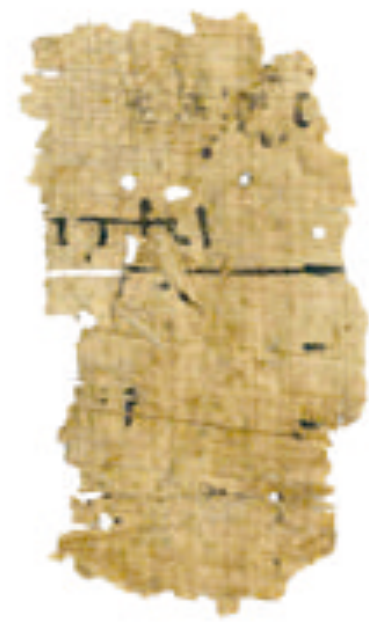

Fr. 4

F. 2 


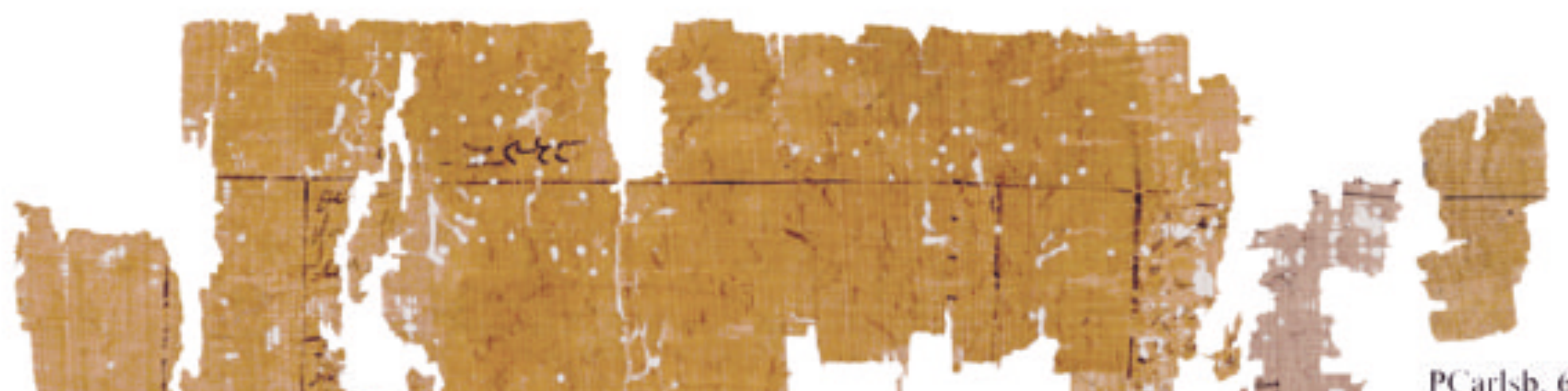

PCarlsb. $673 \mathrm{Fr} .7$

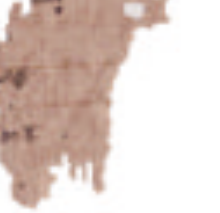

PCarlsb. $673 \mathrm{Fr} .5$

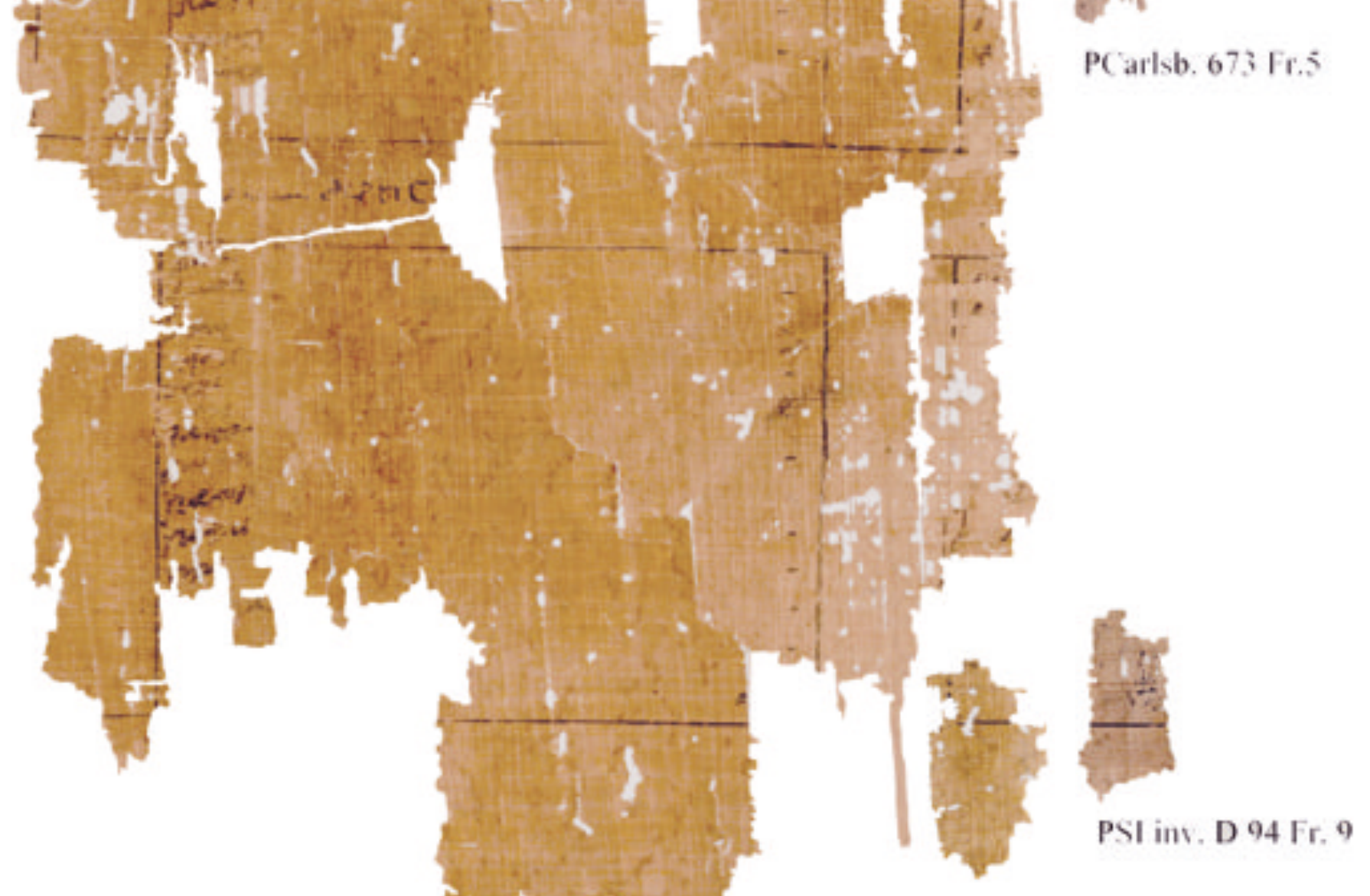

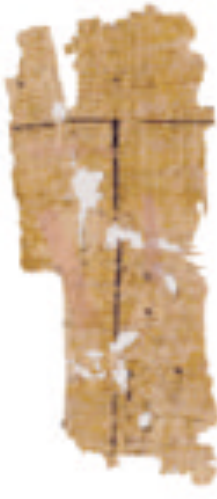

PCarlsb. 673 Fr. 9 


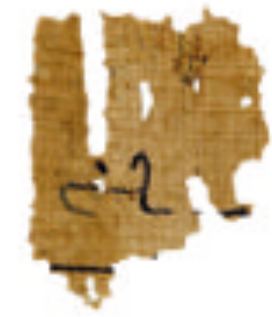

Fr. 3

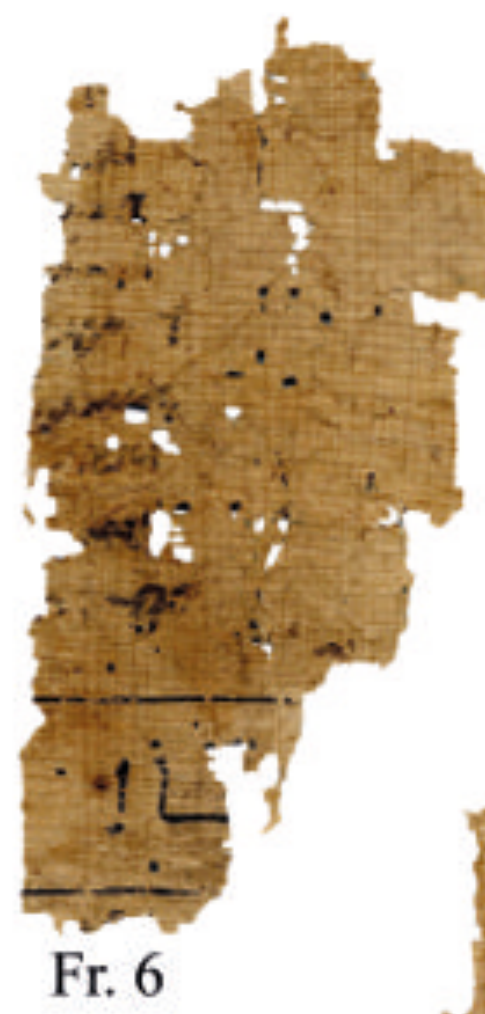

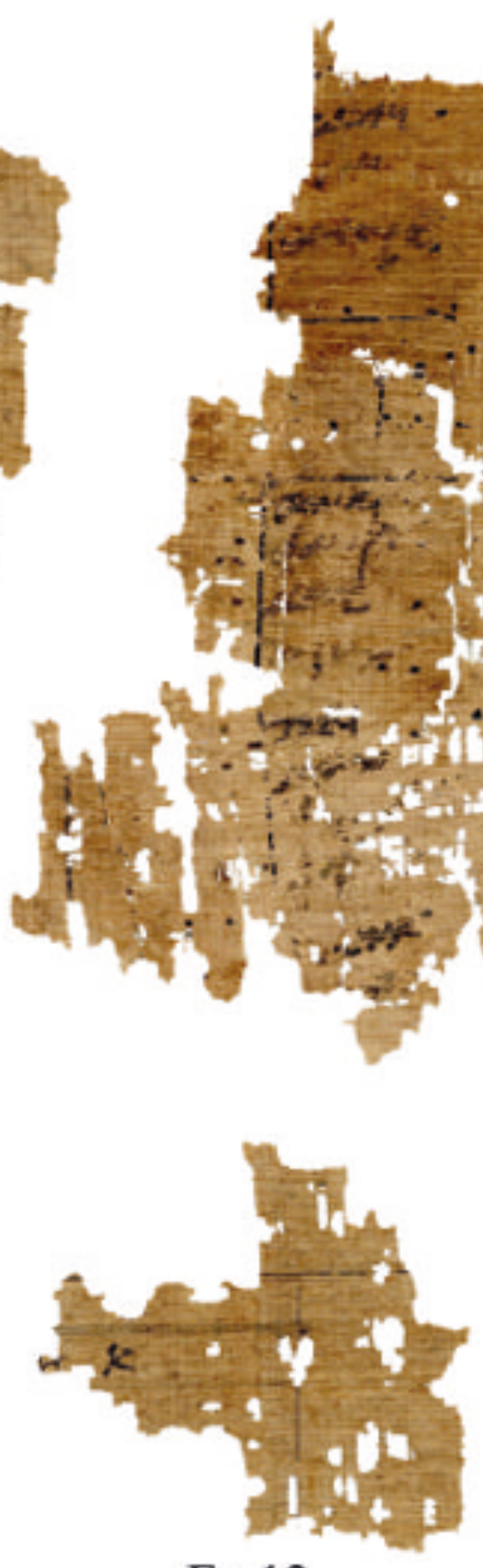

Fr. 12

Fr. 12

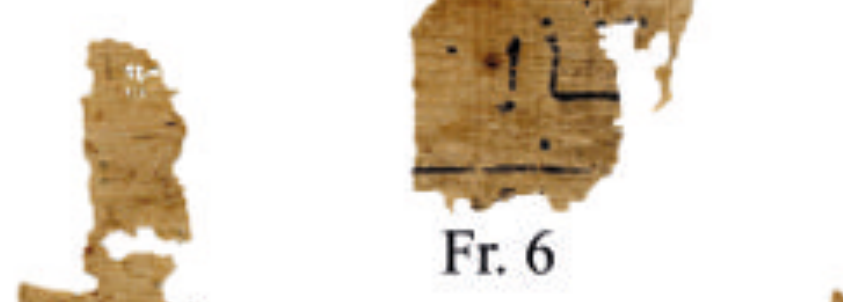

Fr. 10

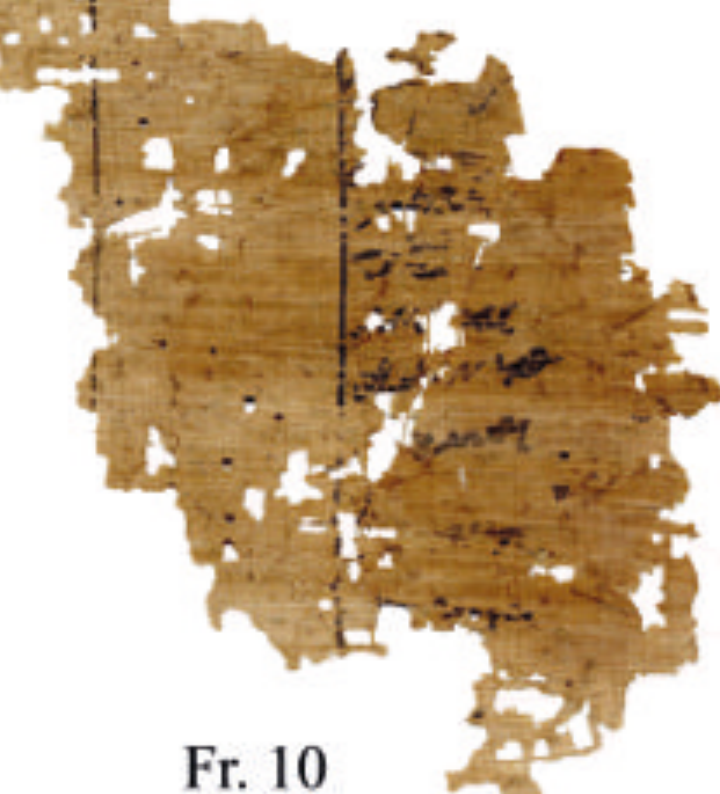

Fr. 7

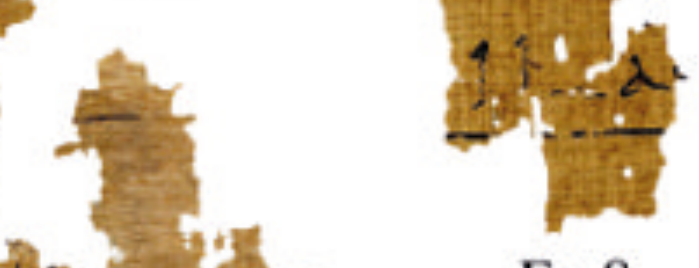

Fr. 8

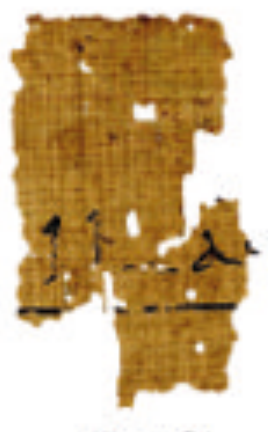




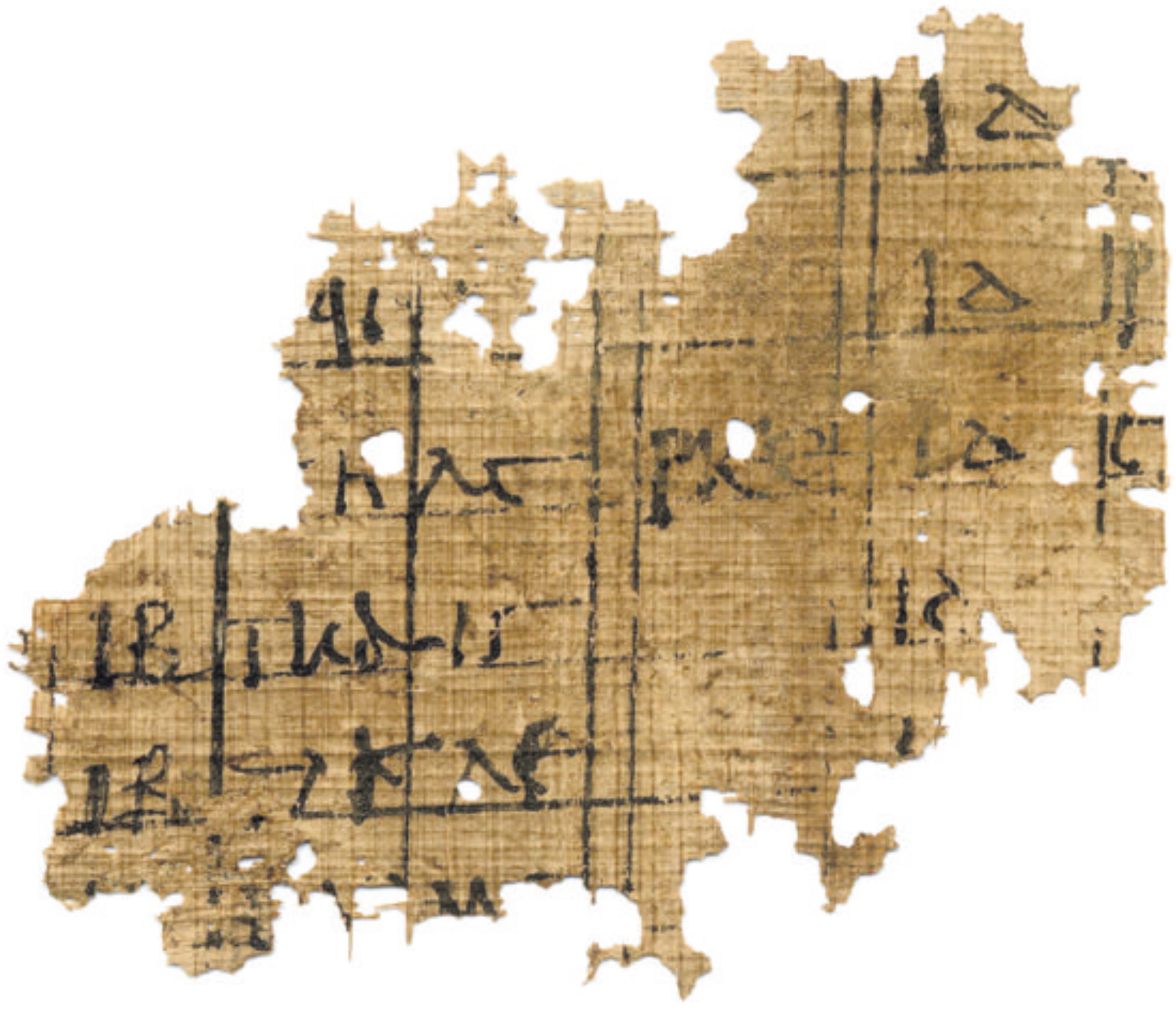

